\title{
Designing Compensation for Distributed Solar Generation: Is Net Metering Ever Optimal?
}

\author{
David P. Brown* and David E. M. Sappington**
}

\begin{abstract}
Electricity customers who install solar panels often are paid the prevailing retail price for the electricity they generate. We demonstrate that this rate of compensation typically is not optimal. A payment for distributed generation $(w)$ that is below the retail price of electricity $(r)$ often will induce the welfare-maximizing level of distributed generation (DG) when the fixed costs of centralized electricity production and the network management costs of accommodating intermittent solar DG are large, and when centralized generation and DG produce similar (pollution) externalities. $w$ can optimally exceed $r$ under alternative conditions. The optimal DG compensation policy varies considerably as industry conditions change. Furthermore, a requirement to equate $w$ and $r$ can reduce aggregate welfare substantially and can generate pronounced distributional effects.
\end{abstract}

Keywords: Electricity pricing, Distributed generation, Net metering

http://dx.doi.org/10.5547/01956574.38.3.dbro

\section{INTRODUCTION}

Distributed generation of electricity (i.e., the "generation of electricity from sources that are near the point of consumption, as opposed to centralized generation sources such as large utilityowned power plants") ${ }^{1}$ is already pervasive in many countries and is expanding rapidly throughout the world. ${ }^{2}$ Although distributed generation (DG) has potential drawbacks, DG is popular in part because it can reduce electricity distribution costs (by moving generation sites closer to final consumers), improve system reliability (by ensuring multiple production sources), limit the amount of capacity required at the primary production site, and reduce generation externalities (e.g., carbon emissions). ${ }^{3}$ One popular form of DG involves the production of electricity from solar panels installed on the roofs of residential buildings. ${ }^{4}$ Homeowners incur the expense of the panels in order to produce electricity which they either consume or sell to the electric utility.

1. American Council for an Energy-Efficient Economy (2014).

2. The World Alliance for Decentralized Energy (2014) summarizes the extent of distributed generation around the world.

3. See Weissman and Johnson (2012), for example. The potential disadvantages of DG include the fact that, because the amount of electricity produced by solar panels varies with the prevailing level of sunshine, backup generation resources and additional ancillary services may be required to maintain network reliability. Furthermore, electricity may not be produced during periods of peak demand, when the cost of centralized electricity production is highest (Kuang et al., 2011).

4. The Solar Electric Power Association (2013) reports that "Between 2011 and 2012, the number of newly installed solar net metering systems [in the U.S.] increased from 61,400 to 89,620 - a $46 \%$ annual growth rate."

* Corresponding author. Department of Economics, University of Alberta, Edmonton, Alberta T6G 2H4 Canada. E-mail: dpbrown@ualberta.ca.

** Department of Economics, University of Florida, Gainesville, FL 32611 USA. E-mail: sapping@ufl.edu.

The Energy Journal, Vol. 38, No. 3. Copyright (C) 2017 by the IAEE. All rights reserved. 
More than four-fifths of U.S. states have implemented net metering policies to encourage DG in their electricity sectors. ${ }^{5}$ Under net metering, the electric utility compensates a customer at the end of each billing period for the customer's net production of electricity (i.e., the difference between the customer's production and consumption of electricity) during the period. Compensation typically reflects the prevailing retail price of electricity, ${ }^{6}$ although in principle it can be set at a different level. ${ }^{7}$

Some states have also adopted feed-in tariffs to promote DG. ${ }^{8}$ Under feed-in tariffs, the utility compensates a customer at a specified rate for all of the electricity he generates. In particular, this rate of compensation — which can differ from the prevailing retail price of electricity-is paid even if a customer's consumption of electricity exceeds his production of electricity. ${ }^{9}$

Although many net metering and feed-in tariff policies have been implemented, controversy about the appropriate compensation for DG abounds. ${ }^{10}$ Some contend that, in light of its many benefits, DG should be encouraged by providing compensation that exceeds the prevailing retail price of electricity. Others argue that compensation for DG at the prevailing retail price of electricity is unduly generous - and so compels customers who do not engage in DG to subsidize those who do-for at least three reasons. First, the prevailing retail price of electricity typically exceeds the system-wide cost saving that a unit of distributed electricity generation provides. This saving is the cost the primary production source (often the utility) avoids when it is not required to produce the electricity generated by the distributed source. ${ }^{11}$ Second, compensation at the retail rate does not charge customers who generate more electricity than they consume for the relevant cost of distributing the excess electricity to other consumers. Third, the electricity supply from several forms of DG (including solar and wind generation) is unreliable because the amount of electricity generated depends heavily on prevailing weather conditions. ${ }^{12}$

Despite the prevalence of DG compensation policies, the economic literature provides little guidance on their optimal design. Several studies (e.g., Couture and Gagnon, 2010; Eid et al., 2014) discuss the strengths and weakness of different DG policies, noting for instance that net metering

5. See the American Public Power Association (APPA) (2013), Linvill et al. (2013), and the Solar Electric Power Association (2013), for example.

6. Under many net metering policies, positive net production of electricity in a given billing period is subtracted from electricity consumption in the next billing period, thereby effectively providing compensation for positive net production that reflects the prevailing retail price of electricity.

7. For example, the DG compensation might reflect the utility's avoided cost of producing electricity. "Net purchase and sale" policies are similar to net metering policies, but allow for continual measurement of and compensation for any net production of electricity.

8. Linvill et al. (2013).

9. Feed-in tariffs generally are set at a specified level for an extended period of time (e.g., ten to twenty years) and so do not change (explicitly or implicitly) as the retail price of electricity changes. The long duration of the specified compensation is intended to encourage investment in DG by guaranteeing the financial payoff from the investment for a long period of time. Yamamoto (2012) provides a useful discussion of net metering, feed-in tariff, and net purchase and sale policies.

10. Cardwell (2012), Kind (2013), Raskin (2013), and Than (2013), among others, review the key arguments in the debate regarding the merits of these policies.

11. Gordon et al. (2006, p. 28) observe that the proper DG "payment should be based on the wholesale power costs that the utility avoids as a result of the availability of power from the DG customer/generator."

12. Consequently, such DG production may not permit the utility to reduce its generating capacity much, if at all. Furthermore, in light of DG "intermittency," the utility may employ a technology that generates substantial losses from environmental externalities to address the transient excess demand for electricity that arises when DG supply falls below its expected level.

Copyright (C) 2017 by the IAEE. All rights reserved. 
programs can advantage DG consumers at the expense of non-DG consumers and reduce the utility's earnings. Some studies (e.g., Darghouth et al., 2011, 2014; Poullikkas, 2013; Eid et al., 2014) simulate the effects of different DG policies. A few studies (e.g., Yamamoto, 2012) model some elements of the critical design problem, but do not fully characterize an optimal DG policy. ${ }^{13}$

The purpose of this research is to begin to fill this void in the literature by characterizing the optimal DG compensation policy in a simple setting where a regulator can set a unit retail price $(r)$ for electricity purchased from a vertically-integrated utility and the compensation $(w)$ the utility must deliver to customers for each unit of electricity they generate using solar DG capacity. ${ }^{14}$ The regulator may also be able to set a fixed retail charge $(R)$ for the right to purchase electricity from the utility. Some customers (" $D$ customers") can install solar DG capacity at their own expense while others (" $N$ customers") do not have this opportunity (perhaps because of limited financial resources or local zoning ordinances that prohibit the installation of solar panels on residential roof tops, for example). Installed DG capacity produces a stochastic supply of electricity. The utility adjusts its electricity supply to meet market demand after observing the amount of electricity supplied via DG. The regulator chooses her policy instruments to maximize the difference between consumer welfare and social losses from environmental externalities (e.g., pollution and climate change) while ensuring non-negative (extranormal) profit for the utility.

We find that when the regulator can set $w, r$, and $R$, the optimal value of $w$ ensures that the rate at which expected DG payments increase as solar DG capacity expands is equal to the sum of the corresponding rates at which: (i) the utility's generation, transmission, distribution, and network management costs decline; and (ii) social losses from environmental externalities decline as DG replaces centralized generation of electricity. $r$ is optimally set to minimize expected weighted deviations between $r$ and the utility's marginal cost of generating electricity. ${ }^{15}$

The optimal values of $w$ and $r$ typically differ. $r$ optimally exceeds $w$, for example, when the fixed costs of centralized electricity production are large, the network management costs associated with integrating intermittent solar DG capacity into the utility's transmission and distribution system are substantial, the utility's marginal cost of generating electricity is largely insensitive to the scale of production, and centralized and distributed generation of electricity entail similar losses from environmental externalities. In contrast, the regulator will optimally set $w$ above $r$ to encourage DG investment when, for instance, the fixed costs of centralized production and network management costs associated with intermittent DG production are small, the marginal cost of centralized production increases relatively rapidly with output, and DG permits a substantial reduction in losses from externalities.

Just as the properties of the optimal DG compensation policy can vary with environment in which the policy is implemented, so can the effects of a "net metering mandate" (that requires

13. Yamamoto (2012) assumes the government first chooses a retail price for electricity and then sets the DG compensation rate to ensure a specified number of customers invest in a fixed level of DG capacity. Consumers do not consider the potential reduction in their electricity bills when they decide whether to install this capacity.

14. An advanced bi-directional smart meter (or multiple traditional smart meters) can be employed to measure separately a household's electricity consumption and the amount of electricity it generates from solar panels. The DG compensation policies proposed in Maine, Minnesota, and Texas call for such measurement (APPA, 2013; Farrell, 2014; Minnesota Department of Commerce, 2014; NCCETC, 2015d). The Institute for Electric Efficiency (IEE, 2014) reports that more than 50 million smart meters had been installed in the U.S. as of July 2014.

15. The weights reflect the price elasticities of demand for $D$ and $N$ customers. If fixed retail charges $(R)$ are not feasible and if the identified values of $w$ and $r$ generate negative expected profit for the utility, then $r$ is increased and $w$ is decreased to ensure the utility's solvency. 
$w$ and $r$ to be identical). To illustrate, first consider a setting in which the optimal value of $w$ (denoted $w^{*}$ ) is less than the optimal value of $r$ (denoted $r^{*}$ ). A net metering mandate in this setting can produce a unit DG payment and retail price $\left(r_{n}\right)$ that exceeds both $w^{*}$ and $r^{*}$. Although the increase in $r$ harms all customers, $D$ customers can experience an overall increase in welfare due to the increased DG compensation they receive. The increase in $w$ also can induce increased solar DG investment and output, with a corresponding reduction in losses from environmental externalities.

In contrast, when $w^{*}$ exceeds $r^{*}$, a net metering mandate can result in an $r_{n}$ below both $w^{*}$ and $r^{*}$. The reduction in $r$ benefits all customers. However, $D$ customers can experience an overall reduction in welfare due to the reduced DG compensation they receive. The reduction in $w$ also can discourage investment in solar DG capacity and result in increased social losses from environmental externalities.

Thus, in contrast to popular claims during policy debates, one cannot state unequivocally that a net metering mandate always benefits $D$ customers and harms $N$ customers. One also cannot state conclusively that such a mandate will reduce social losses from environmental externalities. One general (but apparent) conclusion can be drawn: a net metering mandate typically reduces aggregate expected welfare below the level that can be achieved in the absence of the mandate. More importantly, the welfare reduction can be substantial, and the distributional effects of the mandate can be particularly pronounced.

We develop and explain these findings as follows. Section 2 describes our formal model. Section 3 characterizes the optimal policy in the benchmark setting where electricity production does not generate losses from externalities. Section 4 reviews the changes introduced by losses from externalities. Section 5 employs numerical solutions to illustrate how the optimal DG policy and the effects of a net metering mandate vary with the prevailing industry environment. Section 6 concludes and identifies directions for further research. The Appendix provides details of the analyses that underlie the numerical solutions presented in section 5. The proofs of all formal conclusions are presented in Appendix A in Brown and Sappington (2016).

\section{MODEL}

In the primary interpretation of our model, a regulated vertically-integrated provider ("the VIP") produces and distributes electricity to its customers, consumer $N$ and consumer $D .{ }^{16}$ Each consumer pays unit price $r$ for electricity purchased from the VIP. Each consumer may also pay a fixed fee, $R$, for the right to purchase electricity from the VIP. ${ }^{17}$ When she can set both $r$ and $R$, the regulator employs the former instrument to induce the desired level of electricity consumption while employing the latter instrument to ensure the VIP earns a normal profit. ${ }^{18}$

16. Our qualitative conclusions are unchanged if there are multiple identical $D$ consumers and multiple identical $N$ consumers. Section 6 identifies additional considerations that can arise when there are multiple $D$ consumers who differ from one another. As explained further below, key elements of our analysis remain relevant in settings where the utility does not generate electricity, but rather purchases it in a competitive wholesale electricity market.

17. We abstract from nonlinear prices in part for analytic simplicity and in part because of Ito (2014)'s finding that consumer demand for electricity responds more to the average price of electricity than to its marginal price. Section 6 identifies additional considerations that can arise when nonlinear prices are feasible and when consumers respond to marginal prices.

18. The fixed fee is assumed not to affect the demand for electricity. Because fixed fees often are relatively small in practice, we will analyze the optimal regulatory policy both when the regulator can set a fixed fee and when she cannot do so. Although the fixed fee may serve to recover a portion of the utility's fixed cost of production, the fee is not restricted to this function. We assume all consumers face the same retail charges for electricity. Consequently, the regulator cannot 
Consumer $N$ cannot generate electricity, and so purchases all of the electricity he consumes from the VIP. ${ }^{19}$ Consumer $D$ purchases and installs solar panels in order to produce electricity to supplement or replace electricity purchased from the VIP. The VIP is required to pay consumer $D$ the amount $w$ for each unit of electricity he produces. If $w=r$, then consumer $D$ is paid exactly the retail price of electricity for each unit of electricity he produces, as is common under net metering policies in practice.

After the regulator sets $R, r$, and $w$, consumer $D$ determines the level of solar DG capacity $\left(K_{D}\right)$ he will install. The cost of installing capacity $K_{D}$ is $C_{D}^{K}\left(K_{D}\right)$, which is a strictly increasing, strictly convex function. ${ }^{20}$ To capture the intermittency associated with solar DG, we assume that each unit of DG capacity generates $\theta$ units of electricity, where $\theta \in[\underline{\theta}, \bar{\theta}]$ is the realization of a random state variable with distribution function $F(\theta)$. The corresponding density function, $f(\theta)$, has strictly positive support on $[\underline{\theta}, \bar{\theta}]$, where $0 \leq \underline{\theta}<\bar{\theta} \leq 1$. The expected value of $\theta$ is denoted $\theta^{E}{ }^{21}$

Consumer $j \in\{D, N\}$ derives value $V^{j}(x, \theta)$ from $x$ units of electricity in state $\left.\theta \in \underline{\theta}, \bar{\theta}\right]$. This value is a strictly increasing, strictly concave function of $x$. The state variable $\theta$ can be viewed as a measure of the amount of sunshine that prevails at a specified time in the relevant period. Therefore, in hot climates, for example, higher realizations of $\theta$ often will be associated with higher total and marginal valuations of electricity (to power cooling units). ${ }^{22}$ Consumer $j$ 's demand for electricity in state $\theta$ is $X^{j}(r, \theta)$. Aggregate consumer demand in state $\theta$ is $X(r, \theta)=X^{D}(r, \theta)+X^{N}(r, \theta)>0$.

The VIP incurs both capacity costs and additional operating costs. The VIP's variable cost of generating $Q^{v}$ units of electricity when it has $K_{G}$ units of generating capacity is $C^{G}\left(Q^{v}, K_{G}\right)$. Increased generating capacity reduces at a diminishing rate the VIP's variable and marginal cost of generating electricity. ${ }^{23}$ The VIP's cost of installing $K_{G}$ units of generating capacity is $C^{K}\left(K_{G}\right)$, which is an increasing, convex function. ${ }^{24}$

The VIP also bears transmission and distribution costs, and costs associated with integrating an intermittent generation source into the network. These costs include expenses associated with installing and enhancing voltage and frequency control equipment to handle the dual flow of electricity to and from customer premises. The costs also include expenses required to ensure

impose a higher fixed fee on consumer $D$ even if his DG operations cause the utility to incur higher transmission, distribution, or network management costs. Section 6 discusses alternative formulations.

19. A consumer may be unable to generate electricity for a variety of reasons. For example, local zoning regulations might prohibit the installation of solar panels on rooftops. Alternatively, the location or the architecture of a consumer's residence might not be conducive to efficient solar generation.

20. The increasing marginal cost of generating capacity might reflect in part the limited surface available on a customer's roof. Less than ideal exposure to the sun reduces the electricity a solar panel generates. We abstract from the possibility that consumer $D$ might rent solar panels from the utility or a private company like SolarCity rather than purchase the panels.

21. We assume consumer $D$ always installs some DG capacity $\left(K^{D}>0\right)$ but not enough to serve the entire realized demand for electricity. Thus, the VIP always serves some customers in equilibrium. This will be the case if, for example, $\lim C_{D}^{K^{\prime}}\left(K^{D}\right)=0$ and $C_{D}^{K^{\prime}}\left(K^{D}\right)$ increases sufficiently rapidly as $K^{D}$ increases above 0 . Here and throughout the ensuing $K^{D} \rightarrow 0$ analysis, primes (') denote derivatives.

22. Formally, in hot climates, $\frac{\partial V^{j}(x, \theta)}{\partial \theta} \geq 0$ and $\frac{\partial^{2} V^{j}(x, \theta)}{\partial \theta \partial x} \geq 0$ for all $x \geq 0$ and $\theta \in[\theta, \theta]$, for $j \in\{D, N\}$. These inequalities need not hold more generally. The findings reported below hold even if these inequalities do not hold.

23. Formally, $\frac{\partial C^{G}\left(Q^{v}, K_{G}\right)}{\partial K_{G}}<0, \frac{\partial^{2} C^{G}\left(Q^{v}, K_{G}\right)}{\partial Q^{v} \partial K_{G}}<0$, and $\frac{\partial^{3} C^{G}\left(Q^{v}, K_{G}\right)}{\partial Q^{v} \partial^{2} K_{G}}>0$ for all $Q^{v}>0$.

24. Formally, $C^{K^{\prime}}\left(K_{G}\right)>0$ and $C^{K^{\prime \prime}}\left(K_{G}\right)>0$. We also assume a strictly positive level of generating capacity is optimal. This will be the case if, for example, limit $\left|\frac{\partial C^{G}\left(Q^{v}, K_{G}\right)}{\partial K_{G}}\right|=\infty$ for all $Q^{v}>0$ and $\operatorname{limit}_{K_{G} \rightarrow 0} C^{K^{\prime}}\left(K^{G}\right)=0$. 
network reliability in the presence of an intermittent supply of electricity. These expenses can reflect, for example, the costs of installing and maintaining quick-start natural gas reserve generating capacity. ${ }^{25}$ We will refer to these costs as transmission, distribution, and network management (TDM) costs, $T\left(K_{G}, K_{D}\right){ }^{26}$ For simplicity, we abstract from TDM costs (e.g., line losses) that vary with the levels of electricity supplied rather than the levels of installed generating capacities. ${ }^{27}$

Electricity production can generate social losses from externalities (due to pollution and associated climate change, for instance). $L\left(Q^{v}, Q^{D}\right)$ will denote the magnitude of the loss that arises when the VIP produces $Q^{v}$ units of electricity and consumer $D$ produces $Q^{D}$ units of electricity. $L(\cdot)$ is a non-decreasing function of each of its arguments.

The regulator chooses her policy instruments to maximize the difference between expected consumer welfare and expected social losses from externalities, subject to ensuring non-negative expected profit for the VIP. The regulator's policy instruments are the retail charges for electricity ( $R$ and $r$ ), the unit compensation ( $w$ ) the VIP must deliver to consumer $D$ for the electricity he produces, and the VIP's generating capacity $\left(K_{G}\right)$.

Consumer $N$ 's welfare $\left(U^{N}(\cdot)\right)$ is the difference between the value he derives from the electricity he consumes and the amount he pays for the electricity. Formally, consumer $N$ 's expected welfare is:

$$
E\left\{U^{N}(\cdot)\right\}=\int_{\underline{\theta}}^{\bar{\theta}}\left[V^{N}\left(X^{N}(r, \theta), \theta\right)-r X^{N}(\cdot)\right] d F(\theta)-R .
$$

Consumer D's welfare $\left(U^{D}(\cdot)\right)$ is the sum of the value he derives from the electricity he consumes and the compensation he receives for producing electricity, less the amount he pays for the electricity he purchases from the VIP and his DG capacity costs. Formally, consumer D's expected welfare is:

$$
E\left\{U^{D}(\cdot)\right\}=\int_{\underline{\theta}}^{\bar{\theta}}\left[V^{D}\left(X^{D}(r, \theta), \theta\right)-r X^{D}(\cdot)\right] d F(\theta)-R+w \theta^{E} K_{D}-C_{D}^{K}\left(K_{D}\right) .
$$

As reflected in equation (2), consumer $D$ produces $\theta K_{D}$ units of electricity in state $\theta$ when he has installed $K_{D}$ units of solar DG capacity. The VIP produces the residual demand for electricity. Therefore, expected losses from externalities are:

$$
E\{L(\cdot)\}=\int_{\underline{\theta}}^{\bar{\theta}} L\left(X(r, \theta)-\theta K_{D}, \theta K_{D}\right) d F(\theta) .
$$

The VIP's profit $(\pi)$ is the revenue it secures from selling electricity to consumers $D$ and $N$, less the sum of: (i) the DG compensation it pays to consumer $D$; (ii) the cost of its generating capacity; (iii) its variable cost of generating electricity; and (iv) its TDM costs. Formally, the VIP's expected profit is:

25. These expenses also can include the costs of spinning reserves that vary with the level of installed DG capacity rather than with the level of centralized production of electricity.

26. The ensuing discussion will emphasize the case in which $T(\cdot)$ is strictly increasing in each of its arguments. The analysis in the Appendix allows for the possibility that the VIP's (long run) TDM costs might decline as $K_{D}$ increases if, for instance, the network management costs associated with an intermittent generating source are limited (Cohen et al., 2015).

27. Line losses are relatively small in practice (Parsons and Brinckerhoff, 2012; U.S. Energy Information Administration (EIA), 2014b). Explicit accounting for these variable costs would not affect the key qualitative conclusions reported below. 
$E\{\pi\}=\int_{\underline{\theta}}^{\bar{\theta}}\left[r X(\cdot)-w \theta K_{D}-C^{G}\left(Q^{v}(\cdot), K_{G}\right)\right] d F(\theta)+2 R-C^{K}\left(K_{G}\right)-T\left(K_{G}, K_{D}\right)$.

The regulator's problem, denoted $[\mathrm{RP}]$, is:

$$
\underset{R, r, w, K_{G}}{\operatorname{Maximize}} E\left\{U^{D}(\cdot)+U^{N}(\cdot)\right\}-E\{L(\cdot)\}
$$

subject to: $E\{\pi\} \geq 0$.

[RP] reflects the problem a risk-neutral regulator faces in establishing time-invariant capacities and (nondiscriminatory) prices, recognizing potential variation in consumer demand for electricity and DG supply of electricity over a relatively long planning horizon. [RP] does not account for short-term (e.g., intra-day) variation in demand, and so does not consider such policy instruments as peak load prices. [RP] also does not explicitly incorporate social losses from network outages and does not permit the regulator to choose the prevailing level of network reliability. Instead, the regulator sets her policy instruments to maximize expected consumer welfare, recognizing the TDM costs the utility must incur to ensure the relevant level of network reliability. ${ }^{28}$ Section 6 discusses extensions of the model.

The timing in the model is as follows. The regulator first sets her policy instruments. Consumer $D$ then chooses his solar DG capacity investment. The state is realized next, and DG production occurs. The VIP then produces the realized residual demand for electricity, and performs all required transmission, distribution, and network management services.

Table 1 summarizes the notation in the model.

Before proceeding, we note that although our formal model is designed to characterize optimal DG compensation policies in settings where the utility is vertically-integrated, key elements of our analysis remain relevant in settings where the utility is a transmission and distribution company that procures electricity from a competitive wholesale market. ${ }^{29}$ The increasing marginal cost of procuring electricity in this setting arises because more costly generating units are dispatched (by an independent system operator, for example) as the demand for electricity increases. ${ }^{30}$

28. Generating capacity that is sufficient to meet a system's energy requirements may not be sufficient to meet all instantaneous demand. Consequently, network outages may arise even when network reliability is increased to the point where the marginal social benefit of increased reliability is equal to the corresponding marginal cost.

29. Some suppliers may be able to exercise market power in certain wholesale electricity markets (e.g., Puller, 2007; Bushnell et al., 2008; Mansur, 2008). Independent system operators attempt to limit this market power by, for example, requiring bids to reflect estimates of supplier costs (FERC, 2014). A complete analysis of optimal DG compensation policy in restructured electricity markets should account for potential market power in the generation sector.

30. The utility's investment in generating capacity $\left(K_{G}\right)$ would not be a policy instrument in this interpretation of the model. Furthermore, the marginal cost of procuring electricity would reflect both the marginal generator's physical production cost and the utility's increased payment for inframarginal units as the market-clearing wholesale price of electricity rises. The ensuing analysis would need to be modified in the context of a competitive wholesale electricity market to reflect the fact that the net change in social losses from environmental externalities that arises as DG output replaces utility supply would reflect the externalities associated with production by the marginal (independent) wholesale electricity supplier rather than by the utility. Depending on the extent to which prevailing environmental policies compel electricity generators to internalize the social losses from the environmental externalities they produce, the competitive wholesale price of electricity may reflect relevant social losses from externalities. 
Table 1: Notation

\begin{tabular}{|l|l|}
\hline Notation & \multicolumn{1}{|c|}{ Description } \\
\hline$r$ & Unit retail price of electricity \\
$w$ & Unit DG compensation \\
$R$ & Fixed charge for electricity \\
$K_{G}$ & VIP's production capacity \\
$K_{D}$ & DG consumer's production capacity \\
$\theta$ & Solar capacity utilization factor (state variable) \\
$F(\theta)$ & Distribution function for $\theta$ \\
$X^{j}(\cdot)$ & Consumer $j$ 's demand for electricity $(j \in\{D, N\})$ \\
$X(\cdot)$ & Aggregate demand for electricity \\
$Q^{v}(\cdot)$ & VIP's electricity output \\
$Q^{D}(\cdot)$ & Consumer $D$ 's (DG) electricity output \\
$U^{j}(\cdot)$ & Consumer $j$ 's utility \\
$V^{j}(x, \theta)$ & Consumer $j$ 's valuation of electricity $x$ in state $\theta$ \\
$C_{D}^{K}\left(K_{D}\right)$ & Cost of $K_{D}$ units of DG capacity \\
$C^{K}\left(K_{G}\right)$ & Cost of $K_{G}$ units of VIP capacity \\
$C^{G}(\cdot)$ & VIP's variable generation cost \\
$T(\cdot)$ & VIP's TDM costs \\
$\pi(\cdot)$ & VIP's profit \\
$L(\cdot)$ & Social losses from environmental externalities \\
$E\{\cdot\}$ & Expectations operator \\
\hline
\end{tabular}

\section{BENCHMARK SETTING WITH NO LOSSES FROM EXTERNALITIES}

The key features of the optimal regulatory policy are most transparent when there are no social losses from externalities. We analyze this benchmark setting here and then discuss in section 4 the changes that arise when electricity production generates losses from externalities.

\section{A. No Restrictions on Policy Instruments}

Consider, first, the setting in which the regulator has access to her full set of policy instruments $\left(R, r, w\right.$, and $\left.K_{G}\right)$. The regulator's formal problem in this setting, denoted [RP-F], is problem [RP] with the exception that $L\left(Q^{v}, Q^{D}\right)=0$ for all $Q^{v}$ and $Q^{D}$. Proposition 1 identifies the key features of the optimal policy in this setting.

Proposition 1 At the solution to $[R P-F]$ :

$$
\begin{gathered}
\int_{\underline{\theta}}^{\bar{\theta}}\left|\frac{\partial C^{G}(\cdot)}{\partial K_{G}}\right| d F(\theta)=C^{K^{\prime}}(\cdot)+\frac{\partial T(\cdot)}{\partial K_{G}} ; \\
w \theta^{E}=\int_{\underline{\theta}}^{\bar{\theta}} \frac{\partial C^{G}(\cdot)}{\partial Q^{v}} \theta d F(\theta)-\frac{\partial T(\cdot)}{\partial K_{D}} ; \\
\sum_{j \in\{D, N\}} \int_{\underline{\theta}}^{\bar{\theta}}\left[r-\frac{\partial C^{G}(\cdot)}{\partial Q^{v}}\right] \frac{\partial X^{j}}{\partial r} d F(\theta)=0 ; \text { and }
\end{gathered}
$$




$$
R=\frac{1}{2}\left[\int_{\underline{\theta}}^{\bar{\theta}}\left[C^{G}\left(Q^{v}(\cdot), K_{G}\right)-r X(\cdot)\right] d F(\theta)+w \theta^{E} K_{D}+C^{K}\left(K_{G}\right)+T\left(K_{G}, K_{D}\right)\right] .
$$

Equation (7) indicates that the VIP's generating capacity $\left(K_{G}\right)$ is optimally expanded to the point where its marginal benefit and full marginal cost are equated. The marginal benefit of $K_{G}$ is the associated expected marginal reduction in the VIP's variable cost of generating electricity. The full marginal cost of $K_{G}$ reflects both the marginal cost of securing capacity and the associated marginal TDM costs.

Equation (8) indicates that the unit compensation for DG production $(w)$ is optimally set to induce consumer $D$ to install the efficient level of DG capacity $\left(K_{D}\right)$. This outcome is achieved by equating the consumer's marginal expected return from increasing $K_{D}$ (i.e., $w \theta^{E}$ ) with the marginal expected reduction in the VIP's costs from increasing $K_{D}$. This reduction is the difference between the marginal expected reduction in generation costs and the marginal increase in TDM costs. $^{31}$

Equation (9) indicates that the regulator employs the unit retail price of electricity $(r)$ to induce efficient consumption decisions. Specifically, $r$ is set to ensure that the expected weighted deviations of prices from the incumbent's marginal cost of generating electricity are zero. As is standard under Ramsey pricing of this sort (Ramsey, 1927; Baumol and Bradford, 1970), deviations of price from marginal cost are weighted more heavily when consumer demand is more sensitive to price. Equation (10) indicates that the regulator employs the fixed retail charge to ensure the VIP earns exactly zero profit. $^{32}$

Corollary 1 reports that in settings where the VIP operates with a constant marginal cost of generating electricity, the optimal unit price of electricity $(r)$ exceeds the optimal unit payment for DG output $(w)$, so net metering is not optimal.

Corollary 1. Suppose $\frac{\partial^{2} C^{G}\left(Q^{v}, K_{G}\right)}{\partial\left(Q^{v}\right)^{2}}=0$ for all $Q^{v} \geq 0$ and $K_{G}>0$. Then at the solution to [RP-F], $r=\frac{\partial C^{G}\left(Q^{v}, K_{G}\right)}{\partial Q^{v}}>w=\frac{\partial C^{G}\left(Q^{v}, K_{G}\right)}{\partial Q^{v}}-\frac{1}{\theta^{E}} \frac{\partial T(\cdot)}{\partial K_{D}}$.

When the VIP experiences a constant marginal cost $(c)$ of generating electricity, $r$ is optimally set equal to $c$ in order to induce efficient consumption decisions. $w$ is set below $c$ to equate consumer $D$ 's private marginal return to expanding $K_{D}$ (i.e., $\theta^{E} w$ ) with the corresponding marginal social benefit. This benefit is the expected marginal reduction in the VIP's cost of generating electricity (i.e., $\theta^{E} c$ ) less the marginal increase in the VIP's TDM costs. ${ }^{33}$

31. Observe that $\frac{\partial Q^{v}(\cdot)}{\partial K_{D}}=-\theta$ in state $\theta$ because $Q^{v}(\cdot)=X(\cdot)-\theta K_{D}$. Therefore, $\frac{\partial C^{G}(\cdot)}{\partial Q^{v}} \theta=\frac{\partial C^{G}(\cdot)}{\partial Q^{v}}\left|\frac{\partial Q^{v}(\cdot)}{\partial K_{D}}\right|$. In the setting with a competitive wholesale electricity market, the marginal expected reduction in procurement cost would replace the corresponding reduction in generation cost. As noted above, the marginal procurement cost in a setting with uniformprice auctions would include the marginal cost of the marginal supplier and any increase in payments on inframarginal units of electricity as the market-clearing price rises with increasing demand.

32. It can be shown that when the regulator is able to set $w, r$, and $R$, her inability to dictate the DG capacity investment is not constraining.

33. $w$ would optimally exceed $r$ in this setting if expanded DG capacity reduced the VIP's TDM costs. 
More generally, if expanded DG capacity increases the VIP's TDM costs substantially, then $w$ will optimally be set below $r$ to avoid excessive investment in DG capacity.

Corollary 2. $r>w$ at the solution to $[R P-F]$ if $T\left(K_{G}, K_{D}\right)$ increases sufficiently rapidly with $K_{D}$ for all $K_{G}, K_{D} \geq 0$.

\section{B. No Fixed Retail Charge is Permitted}

In practice, the fixed charge $(R)$ imposed on consumers often is small relative to the average fixed cost of supplying electricity. ${ }^{34}$ Limited fixed charges may reflect income distribution concerns, for example. ${ }^{35}$ To illustrate the changes that arise when the regulator has limited ability to impose a fixed retail charge, Proposition 2 characterizes the solution to [RP-r], which is problem [RP-F] with the exception that $R$ is constrained to be 0 . The proposition refers to $\lambda_{r}$, which is the Lagrange multiplier associated with constraint (6).

Proposition 2. Equation (7) holds at the solution to [RP-r]. Furthermore:

$$
\begin{aligned}
& w \theta^{E}=\int_{\underline{\theta}}^{\bar{\theta}} \frac{\partial C^{G}(\cdot)}{\partial Q^{v}} \theta d F(\theta)-\frac{\partial T(\cdot)}{\partial K_{D}}-\left[\frac{\lambda_{r}-1}{\lambda_{r}}\right] \frac{\theta^{E} K_{D}}{\partial K_{D} / \partial w} ; \\
& \sum_{j \in\{D, N\}} \int_{\underline{\theta}}^{\bar{\theta}}\left[r-\frac{\partial C^{G}(\cdot)}{\partial Q^{v}}\right]\left|\frac{\partial X^{j}}{\partial r}\right| d F(\theta)=\left[\frac{\lambda_{r}-1}{\lambda_{r}}\right] \sum_{j \in\{D, N\}} \int_{\underline{\theta}}^{\bar{\theta}} X^{j}(\cdot) d F(\theta) ;
\end{aligned}
$$

and

$$
r=\frac{w \theta^{E} K_{D}+\int_{\underline{\theta}}^{\bar{\theta}} C^{G}\left(Q^{v}(\cdot, \theta), K_{G}\right) d F(\theta)+C^{K}\left(K_{G}\right)+T\left(K_{G}, K_{D}\right)}{\int_{\underline{\theta}}^{\bar{\theta}} X(\cdot, \theta) d F(\theta)} .
$$

Equations (11) and (12) reveal that when the values of $r$ and $w$ identified in Proposition 1 would impose a loss on the VIP (so $E\{\pi\}<0$ ), the regulator adjusts $r$ and $w$ to eliminate this loss. Specifically, when $\lambda_{r}>1$ at the solution to [RP-r], the regulator increases $r$ in order to enhance the VIP's revenue and reduces $w$ in order to limit the DG payments the VIP must deliver to consumer $D .^{36}$ Equation (13) indicates that $r$ is optimally set equal to the VIP's expected average cost to ensure zero expected profit for the VIP.

When the regulator is unable to set a fixed retail charge $(R)$, she must employ $r$ and $w$ to induce efficient consumption and investment decisions and to secure nonnegative profit for the VIP. The multiple roles that $r$ and $w$ must play in this setting complicate attempts to systematically rank the optimal values of $r$ and $w$. However, as Proposition 3 reports, $r$ is optimally set above $w$ when

34. Borenstein (2014) reports that two of the three major electric utilities in California (Pacific Electric \& Gas and San Diego Gas \& Electric) impose no fixed retail charge. The third utility (Southern California Edison) imposes a monthly fixed charge of only $\$ 0.99$.

35. If all fixed costs of supplying electricity were recovered via fixed retail charges, customers who consume little electricity (perhaps because their limited income compels them to consume only minimal housing resources) would face large monthly charges for electricity.

36. Additional restrictions on demand and cost functions are required to rule out the possibility that the regulator might increase $w$ in order to reduce the VIP's costs by shifting electricity production from the VIP to consumer $D$. 
consumer demand for electricity is sufficiently price inelastic and the VIP's marginal cost of generating electricity is sufficiently insensitive to the level of generation. The proposition refers to Assumptions 1 and 2 which, for tractability, introduce an iso-elastic demand function and a polynomial cost function of degree $n \geq 2$.

Assumption 1. $X^{j}(r, \theta)=m_{j}\left[\beta_{0 j}+\theta^{\beta_{j}}\right] r^{\alpha_{j}}$ for $j=D, N$, where $\alpha_{j} \leq 0, m_{j}>0, \beta_{0 j}>0$, and $\beta_{j}$ are parameters.

Assumption 2. $C^{G}\left(Q^{v}, K_{G}\right)=c\left(K_{G}\right) Q^{v}+\sum_{i=2}^{n} b_{i}\left[Q^{v}\right]^{i}$ where $b_{2}, \ldots, b_{n}$ are parameters.

Proposition 3. $r>w$ at the solution to [RP-r] if Assumptions 1 and 2 hold, $\alpha_{j}$ is sufficiently close to zero for $j=D, N$, and either: (i) $b_{i}$ is sufficiently close to zero for all $i=2, \ldots, n$; or (ii) the VIP's generation capacity costs $\left(C^{K}\left(K_{G}\right)\right)$ and TDM costs $\left(T\left(K_{G}, K_{D}\right)\right)$ are sufficiently large.

When consumer demand for electricity is largely insensitive to its price, the regulator employs $r$ primarily to hold the VIP to zero expected profit, and so sets $r$ equal to the VIP's average cost of operation. The regulator employs $w$ primarily to induce consumer $D$ to install the efficient level of DG capacity $\left(K_{D}\right)$. She does so by setting $w$ below the VIP's (nearly constant) marginal cost of generating electricity, thereby accounting for the increase in TDM costs the VIP incurs as $K_{D}$ increases. Consequently, $r$ exceeds $w$ under the optimal policy. The numerical solutions presented in section 5 and the Appendix indicate that $r$ often exceeds $w$ under the optimal policy even when the special conditions identified in Proposition 3 do not hold.

\section{THE SETTING WITH LOSSES FROM EXTERNALITIES}

The conclusions reported in section 3 are modified in intuitive and straightforward fashion when electricity production generates social losses from externalities $(L(\cdot))$. To illustrate, consider the setting where the regulator can employ her full set of policy instruments $\left(R, r, w\right.$, and $\left.K_{G}\right)$. The optimal policy in this setting is characterized in Proposition 4 and its corollaries.

Proposition 4. Equations (7) and (10) hold at the solution to [RP]. Furthermore:

$$
\begin{gathered}
w \theta^{E}=\int_{\underline{\theta}}^{\bar{\theta}}\left[\frac{\partial C^{G}(\cdot)}{\partial Q^{v}}+\frac{\partial L(\cdot)}{\partial Q^{v}}-\frac{\partial L(\cdot)}{\partial Q^{D}}\right] \theta d F(\theta)-\frac{\partial T(\cdot)}{\partial K_{D}} \text {, and } \\
\sum_{j \in\{D, N\}} \int_{\underline{\theta}}^{\bar{\theta}}\left[r-\left(\frac{\partial C^{G}(\cdot)}{\partial Q^{v}}+\frac{\partial L(\cdot)}{\partial Q^{v}}\right)\right] \frac{\partial X^{j}}{\partial r} d F(\theta)=0 .
\end{gathered}
$$

Corollary 3. $r>w$ at the solution to $[R P]$ if $T\left(K_{G}, K_{D}\right)$ increases sufficiently rapidly with $K_{D}$ for all $K_{G}, K_{D} \geq 0$.

Corollary 4. Suppose $\frac{\partial^{2} C^{G}\left(Q^{v}, K_{G}\right)}{\partial\left(Q^{v}\right)^{2}}=\frac{\partial^{2} L\left(Q^{v}, Q^{D}\right)}{\partial\left(Q^{v}\right)^{2}}=\frac{\partial^{2} L\left(Q^{v}, Q^{D}\right)}{\partial\left(Q^{D}\right)^{2}}=0$ for all $Q^{v} \geq 0, Q^{D} \geq 0$, and $K_{G}>0$. Then at the solution to $[R P]$ : 


$$
\begin{aligned}
& r=\frac{\partial C^{G}\left(Q^{v}, K_{G}\right)}{\partial Q^{v}}+\frac{\partial L\left(Q^{v}, Q^{D}\right)}{\partial Q^{v}} \\
& >w=\frac{\partial C^{G}\left(Q^{v}, K_{G}\right)}{\partial Q^{v}}+\frac{\partial L\left(Q^{v}, Q^{D}\right)}{\partial Q^{v}}-\frac{\partial L\left(Q^{v}, Q^{D}\right)}{\partial Q^{D}}-\frac{1}{\theta^{E}} \frac{\partial T(\cdot)}{\partial K_{D}} .
\end{aligned}
$$

Equation (14) indicates that in order to induce consumer $D$ to install the efficient DG capacity $\left(K_{D}\right), w$ is set to equate $w \theta^{E}$, the consumer's marginal expected financial return from $K_{D}$, and the associated marginal social benefit from $K_{D}$. This marginal social benefit is the sum of the marginal reduction in the VIP's costs and the marginal expected net reduction in losses from externalities as electricity generation is shifted from the VIP to consumer $D$.

Equation (15) indicates that in order to induce efficient electricity consumption, $r$ is set to equate to 0 weighted deviations of $r$ from the social marginal cost of electricity generation by the VIP. This social marginal cost is the sum of the VIP's marginal cost of generating electricity and the marginal social loss from externalities resulting from electricity generation by the VIP.

Corollary 3 reflects the fact that $w$ is optimally reduced below $r$ to avoid excessive investment in $K_{D}$ when such investment increases TDM costs substantially. Corollary 4 reports that $r$ also optimally exceeds $w$ when the VIP operates with a constant marginal cost of generating electricity and where social losses from externalities increase linearly with electricity production. In this case, $r$ is set equal to the social marginal cost of electricity production by the VIP $\left(\frac{\partial C^{G}(\cdot)}{\partial Q^{v}}+\frac{\partial L(\cdot)}{\partial Q^{v}}\right)$ in order to induce efficient consumption decisions. To induce efficient investment in $K_{D}, w$ is set to equate consumer $D$ 's marginal expected return from $K_{D}$ (i.e., $w \theta^{E}$ ) and the marginal social benefit of $K_{D}$. This benefit is the sum of the expected marginal reduction in the VIP's costs $\left(E\left\{\frac{\partial C^{G}(\cdot)}{\partial Q^{v}}\left|\frac{\partial Q^{v}}{\partial K_{D}}\right|-\frac{\partial T(\cdot)}{\partial K_{D}}\right\}\right)$ and the expected marginal reduction in social losses from externalities as electricity production is shifted from the VIP to consumer $D$ $\left(E\left\{\frac{\partial L(\cdot)}{\partial Q^{v}}\left|\frac{\partial Q^{v}}{\partial K_{D}}\right|-\frac{\partial L(\cdot)}{\partial Q^{D}} \frac{\partial Q^{D}}{\partial K_{D}}\right\}\right) \cdot{ }^{37}$

Conclusions analogous to those derived in section 3.B persist when the regulator cannot set a fixed retail charge for electricity in the presence of social losses from externalities $(L(\cdot))$. To illustrate, it is readily verified that $r$ optimally exceeds $w$ when the conditions specified in Proposition 3 hold and the rate at which $L(\cdot)$ increases with $Q^{v}$ is not too much greater than the rate at which $L(\cdot)$ increases with $Q^{D}{ }^{38}$ The numerical solutions presented in section 5 and the Appendix indicate that $r$ optimally exceeds $w$ more generally (but not always) in this setting.

The numerical solutions presented in the Appendix also reveal that $w$ increases as the relative marginal social loss from externalities due to centralized production by the VIP $\left(\frac{\partial L(\cdot)}{\partial Q^{v}}-\frac{\partial L(\cdot)}{\partial Q^{D}}\right)$ increases. (See Figure A13.) The increase in $w$ encourages expanded investment

37. $w$ could exceed $r$ in the setting of Corollary 4 if expanded DG capacity reduced the VIP's TDM costs sufficiently rapidly.

38. The regulator may set $w$ above $r$ if $\frac{\partial L(\cdot)}{\partial Q^{v}}$ substantially exceeds $\frac{\partial L(\cdot)}{\partial Q^{D}}$. A relatively high value of $w$ can induce substantial investment in DG capacity which limits the VIP's expected electricity production. 
in DG capacity and corresponding increased production by the relatively "clean" source of electricity.

\section{NUMERICAL SOLUTIONS}

We now examine in more detail the optimal DG compensation policy and the impact of a net metering mandate (which requires $w$ and $r$ to be identical) in two illustrative, stylized settings. The settings employ data from California and Ohio to contrast outcomes in a "baseline" setting where the utility installs substantial capacity to serve a relatively large number of customers and in a "smaller market" setting where the utility employs less capacity to serve a smaller number of customers. ${ }^{39}$ We begin by specifying tractable functional forms and representative parameter values for the baseline setting.

Recall that the distribution of the state variable $(\theta)$ reflects variation in the production of electricity from installed DG capacity. To specify this distribution, we first plot the ratio of the MW's of electricity produced by photo-voltaic (PV) panels to the year-end installed generating capacity $\left(\bar{K}_{D}=3,254 \mathrm{MW}\right)$ of PV panels in California for each of the 8,760 hours in $2014 .{ }^{40} \mathrm{We}$ then employ maximum likelihood estimation to fit a distribution to the 4,443 (49.4\%) of the observations that are strictly positive. Standard tests reveal that the beta distribution with parameters $(1.165,1.204855)$ fits the data well, so this distribution is employed as $f(\theta)$ in the ensuing analysis. ${ }^{41}$

Consumer demand for electricity is assumed to be iso-elastic. Specifically, $X^{j}(r, \theta)=$ $m_{j}\left[1+\theta^{\beta_{j}}\right] r^{\alpha_{j}}$ for $j \in\{D, N\}$, where $m_{j}>0, \alpha_{j}<0$, and $\beta_{j}$ are parameters. ${ }^{42}$ Reflecting estimates of the price elasticity of demand for electricity in the literature, we initially assume $\alpha_{D}=\alpha_{N}=-0.25 .{ }^{43}$ $\beta_{j}$ can be viewed as a measure of the sensitivity of electricity demand to solar intensity. We initially set $\beta_{D}=\beta_{N}=0$ in light of the fact that increased sunshine and associated higher temperatures can either increase the demand for electricity to power cooling units in summer months or reduce the demand for electricity to power heating units in winter months.

We set $m_{D}$ and $m_{N}$ in the baseline setting to equate the equilibrium expected demand in the model with $\bar{X}=25,391$ (MWh), the average hourly consumption of electricity in California in 2014. ${ }^{44}$ Formally, $m_{j}$ is chosen to ensure $E\left\{m_{j}\left[1+\theta^{\beta_{j}}\right] \tilde{r}^{\alpha_{j}}\right\}=\eta_{j} \bar{X}$ for $j \in\{D, N\}$, where $\eta_{D}$ denotes

39. The ensuing analysis is not intended to characterize actual or likely outcomes in California or Ohio, in part because the institutional settings in these states do not match our model precisely. In particular, portions of the electricity sectors in these states have been restructured and consumers have a choice among retail suppliers.

40. The data on PV output are derived from the California Independent System Operator (CAISO) (2015b). The statistic on PV capacity is drawn from California Solar Statistics (2015).

41. The tests are the chi-squared, Kolmogorov-Smirnov, and Anderson-Darling tests. These tests also reveal that the generalized extreme value (GEV) distribution with parameter values $(0.4827,0.3088,-0.7135)$ fits the data reasonably well. Findings very similar to those reported below arise when this GEV distribution replaces the identified beta distribution.

42. This relationship is assumed to hold for $r \leq r^{m}$. We assume $X^{j}(\cdot)=0$ for $r>r^{m}$ to ensure finite values for $E\left\{U^{j}\right\}$, $j \in\{D, N\}$. We set $r^{m}=800$, reflecting particularly high estimates of customer valuations of lost load (London Economics International, 2013).

43. Estimates of the short-run price elasticity of demand for electricity for residential consumers range from -0.13 (Paul et al., 2009) to -0.20 (Bohi and Zimmerman, 1984) to -0.24 (Bernstein and Griffen, 2006) to - 0.26 (Narayan and Smyth, 2005), to -0.35 (Espey and Espey, 2004). King and Chatterjee (2003) and Wade (2003) report corresponding estimates in the ranges of $[-0.34,-0.13]$ and $[-0.34,-0.20]$, respectively. Corresponding long-run estimates reflect substantially more elastic demand (e.g., between -0.40 (Paul, 2009) and -0.85 (Espey and Espey, 2004)). Commercial and industrial customers typically exhibit less elastic demands for electricity (e.g., Wade, 2003; Taylor et al., 2005; Paul et al., 2009).

44. $\bar{X}$ is the sum of: (i) $\bar{Q}_{v}=24,577 \mathrm{MWh}$, the average amount of electricity sold hourly by California utilities in 2014 (CAISO, 2015a); and (ii) the estimated average hourly electricity generated from solar DG in California in 2014. This latter 
the fraction of demand accounted for by customers who undertake some distributed generation of electricity, $\eta_{N}=1-\eta_{D}$, and $\tilde{r}=143.8165$ reflects the average unit retail price of electricity $(\$ / \mathrm{MWh})$ in California in 2014 (California Public Utilities Commission, 2015). We initially assume $\eta_{D}=$ 0.1 to reflect the potential deployment of PV panels in the U.S. in the near future. ${ }^{45}$

The VIP's capacity costs are assumed to be quadratic, i.e., $C^{K}\left(K_{G}\right)=a_{K} K_{G}+b_{K}\left(K_{G}\right)^{2}$. Estimates of the cost of the generation capacity required to produce a MWh of electricity range from $\$ 16.1 / \mathrm{MWh}$ for a conventional combined cycle natural gas unit to $\$ 81.9 / \mathrm{MWh}$ for a nuclear facility (EIA, 2015a). We initially set $a_{K}=16.1$ to reflect the lower bound of this range. We also set $b_{K}=$ 0.00045 to ensure that the marginal cost of capacity required to generate a MWh of electricity is $\$ 81.9$ at the observed level of centralized non-renewable generation capacity in California in 2014 $\left(\bar{K}_{G}=72,926 \mathrm{MW}\right)$ (California Energy Commission, 2015).

For simplicity, the VIP's TDM costs are assumed to be linear, i.e., $T\left(K_{G}, K_{D}\right)=a_{T}^{G} K_{G}+$ $a_{T}^{D} K_{D}$. Utility transmission capacity costs associated with generating a MWh of electricity are estimated to be between $\$ 1.2$ and $\$ 3.5$ for centralized, non-renewable generation and between $\$ 4.1$ and $\$ 6.0$ for PV generation (EIA, 2015a). To reflect these estimates, we initially assume $a_{T}^{G}=2.35$ and $a_{T}^{D}=5.05 .^{46}$

We take the VIP's cost of generating $Q^{v}$ units of electricity when it has $K_{G}$ units of capacity to be $C^{G}\left(Q^{v}, K_{G}\right)=\left[a_{v}+\frac{c_{v}}{K_{G}}\right] Q^{v}+b_{v}\left(Q^{v}\right)^{2}$, where $a_{v}, b_{v}$, and $c_{v}$ are positive constants. This formulation implies that increased capacity reduces the VIP's cost of generating electricity at a diminishing rate. ${ }^{47}$ We initially set $b_{v}=0.003$ and $a_{v}+\frac{c_{v}}{K_{G}}=28.53$, reflecting Bushnell (2007)'s estimates. ${ }^{48}$ The initial value of $c_{v}$ is chosen to equate the observed marginal benefit $\left(\frac{c_{v} \bar{Q}^{v}}{\left(\bar{K}_{G}\right)^{2}}\right)$ and marginal cost $\left(a_{K}+2 b_{K} \bar{K}_{G}+a_{T}^{G}\right)$ of VIP capacity. ${ }^{49}$

The cost of installing $K_{D}$ units of DG capacity is assumed to be $C_{D}^{K}\left(K_{D}\right)=a_{D} K_{D}+$ $b_{D}\left(K_{D}\right)^{2}$. Estimates of the unsubsidized cost of residential photo-voltaic (PV) capacity vary between $\$ 100$ and $\$ 400 / \mathrm{MWh}$ (Branker et al., 2011; EIA, 2015a). ${ }^{50}$ Application of the 30 percent federal

estimate is $25.0 \%$ of $\bar{K}_{D}$, the 3,254 MW of PV capacity installed in California at year end 2014. The 25.0\% represents $49.4 \%$ of the mean of $\theta$ under the identified beta distribution. (Recall that $49.4 \%$ of the 8,760 DG output observations in the sample were non-zero.)

45. $10.6 \%$ of consumers undertook some DG of electricity in Hawaii in 2014. The corresponding percentages are $2 \%$ in California and $1.6 \%$ in Arizona (EIA, 2015b). Schneider and Sargent (2014) report rapid growth in the installation of solar panels in recent years. Borenstein (2015) reports that, on average, households that engage in the DG of electricity consume more electricity than do households that do not undertake DG.

46. Estimates of TDM costs vary widely (Cohen et al., 2015) and $T(\cdot)$ in our model can incorporate a variety of network management costs associated with solar DG. Consequently, the analysis in the Appendix that examines the impact of variations in $a_{T}^{D}$ may be particularly relevant.

47. Formally, $\frac{\partial C^{G}(\cdot)}{\partial K_{G}}=-\frac{c_{v} Q^{v}}{\left(K_{G}\right)^{2}}<0$ and $\frac{\partial^{2} C^{G}(\cdot)}{\partial K_{G}^{2}}=\frac{2 c_{v} Q^{v}}{\left(K_{G}\right)^{3}}>0$, which implies $\frac{\partial}{\partial K_{G}}\left|\frac{\partial C^{G}(\cdot)}{\partial K_{G}}\right|<0$.

48. Employing a cost function of the form $C\left(Q^{v}\right)=a Q^{v}+b\left(Q^{v}\right)^{2}$, Bushnell (2007) estimates $a=28.53$ and $b=0.003$. These estimates for California reflect relatively extensive use of hydro and nuclear generating units.

49. Recall equation (7). Also recall $\bar{Q}^{v}=24,577 \mathrm{MWh}$ is the average amount of electricity sold hourly by California utilities in 2014, and $\bar{K}_{G}=72,926$ is the MW of centralized non-renewable generation capacity in California at year-end 2014. Thus, the initial value for $c_{v}$ (and hence $a_{v}$ ) reflects the assumption that the welfare-maximizing level of capacity in the model is $\bar{K}_{G}$.

50. The variation in these estimates reflects variation in the underlying assumptions. To illustrate, the useful life of a solar PV panel is assumed to be between 20 and 30 years, and the annual rate of panel degradation is assumed to be between 
Table 2: Outcomes in the Baseline Setting

\begin{tabular}{|l|c|c|c|c|c|c|c|l|}
\hline Problem & $r$ & $w$ & $K_{G}$ & $K_{D}$ & $E\left\{U^{N}\right\}$ & $E\left\{U^{D}\right\}$ & $E\{L\}$ & $E\{W\}$ \\
\hline$[$ RPE- $r]$ & 273.4 & 193.9 & 67,974 & 5,782 & 8,779 & 1,006 & 425 & 9,360 \\
\hline$[$ RPE- $r$ NM $]$ & 313.7 & 313.7 & 61,963 & 21,544 & 8,006 & 1,318 & 329 & 8,995 \\
\hline
\end{tabular}

income tax credit (ITC) reduces these estimates to between $\$ 70$ and $\$ 280 / \mathrm{MWh}$. State subsidies further reduce these estimates to between $\$ 45$ and \$255/MWh (NCCETC, 2015a,b,c). We initially set $a_{D}=150$, the midpoint of this lattermost range of cost estimates. We also set $b_{D}=0.0038$ to ensure ensure that the marginal cost of DG capacity when $K_{D}=\bar{K}_{D}=3,254$ (i.e., $a_{D}+2 b_{D} \bar{K}_{D}$ ) is 175 , the midpoint of the range of estimated costs after applying the ITC.

Finally, we assume there are no social losses from externalities associated with solar DG. In addition, for simplicity, the corresponding losses are assumed to increase linearly with electricity produced by the VIP, ${ }^{51}$ so $L\left(Q^{v}, Q^{D}\right)=e_{v} Q^{v}$. We initially set $e_{v}=21.029$ to reflect the estimated unit loss from environmental externalities associated with production by a natural gas generating unit. ${ }^{52}$ This unit loss is the product of $\$ 38$, the estimated social cost of a metric ton of $\mathrm{CO}_{2}$ emissions (EPA, 2013), and the metric tons of $\mathrm{CO}_{2}$ emissions that arise when a natural gas unit is employed to produce a MWh of electricity. ${ }^{53}$

Using these parameter values, we solve numerically for the values of $r, w$, and $K_{G}$ (and the associated equilibrium value of $K_{D}$ ) that solve problems [RPE- $r$ ] and [RPE- $\left.r \mathrm{NM}\right] .{ }^{54}$ The former problem is problem [RP] where fixed retail charges are not feasible (so $R=0$ ). The latter problem is the same problem under the net metering $(w=r)$ mandate. Table $2^{55}$ records the key outcomes at the solutions to these problems in this baseline setting. $E\{W\}$ in the table denotes expected welfare, which is the regulator's objective function, as specified in equation (5).

Four elements of Table 2 warrant emphasis. First, the unit retail price of electricity $(r)$ is optimally set well $(41 \%)$ above the unit DG payment $(w)$, so net metering is not optimal. The relatively high value of $r$ enables the VIP to secure the revenue required to offset capacity costs, generation costs, and DG payments. Second, a net metering mandate increases both $r$ and $w$. One might suspect that the mandate would cause $r$ to decline and $w$ to increase toward an intermediate

$0.5 \%$ and $1 \%$. In addition, the annual discount rate is asssumed to be between $2 \%$ and $8 \%$, and system installation costs are assumed to be between $\$ 4.70$ and $\$ 7.70$ per watt (at peak production).

51. In practice, social losses from externalities often increase nonlinearly with centralized electricity production. Marginal social losses tend to be: (i) small when the utility employs renewable or hydro sources to generate base load levels of electricity; (ii) large when the utility dispatches coal-fired units to produce additional, intermediate levels of electricity; and (iii) moderate when the utility dispatches natural gas units to serve peak demand.

52. In practice, utilities often employ natural gas units to satisfy peak electricity demand. The sensitivity analysis in the Appendix accounts for the possibility that DG production might displace centralized production that employs an alternative (e.g., coal) technology.

53. EIA (2014a) estimates that 1.22 pounds of $\mathrm{CO}_{2}$ are emitted when a $\mathrm{kWh}$ of electricity is produced using a natural gas generating unit. This estimate is multiplied by 1,000 to convert kWhs to MWhs, and divided by 2,204.62 to convert pounds to metric tons. Thus, $e_{v}=38[1.22] \frac{1,000}{2,204.62}=21.029$.

54. The solutions are generated using Mathematica, as explained more fully in the Appendix.

55. The values of $E\left\{U^{N}\right\}, E\left\{U^{D}\right\}, E\{L\}$, and $E\{W\}$ in Table 2 and in all successive tables are expressed in thousands. The entries in all tables are rounded to the nearest integer. 
Table 3: Outcomes in the Smaller Market Setting

\begin{tabular}{|l|c|c|c|c|c|c|c|c|}
\hline Problem & $r$ & $w$ & $K_{G}$ & $K_{D}$ & $E\left\{U^{N}\right\}$ & $E\left\{U^{D}\right\}$ & $E\{L\}$ & $E\{W\}$ \\
\hline$[$ RPE- $r]$ & 163.1 & 203.3 & 32,623 & 7,019 & 9,320 & 1,081 & 400 & 10,001 \\
\hline$[$ RPE- $r$ NM $]$ & 161.7 & 161.7 & 33,475 & 1,536 & 9,347 & 1,041 & 429 & 9,958 \\
\hline
\end{tabular}

level. However, as $w$ increases, the associated increase in DG compensation creates a financial deficit for the VIP. $r$ is optimally increased above its original level to ensure the VIP secures a normal profit. As Table 2 illustrates, the optimal values of $w$ and $r$ that satisfy the net metering mandate can substantially exceed their corresponding values in the absence of the mandate.

Third, the substantial $(62 \%)$ increase in $w(=r)$ under net metering induces a pronounced (273\%) increase in DG capacity $\left(K_{D}\right)$. Centralized generation capacity $\left(K_{G}\right)$ is reduced, but by less than the increase in $K_{D}$, in part due to the intermittency associated with solar DG production. Consequently, total industry capacity increases by $13 \%$ (from 73,756 to 83,507 ). The increase in the fraction of electricity derived from solar DG reduces the social losses from externalities (by $23 \%$ ). Fourth, the increase in $w$ under net metering causes consumer $D$ 's expected utility to increase by $31 \%$. In contrast, the increase in $r$ causes consumer $N$ 's expected utility to decline by $9 \%$. On balance, the net metering mandate reduces expected welfare by $3.9 \%$.

To illustrate the different qualitative conclusions that can arise under different circumstances, consider a setting where the VIP employs less capacity to serve a smaller market, as in Ohio, for example. ${ }^{56}$ Specifically, suppose the demand parameters $\left(m_{j}\right)$ are chosen to ensure $E\left\{m_{j}\left[1+\theta^{\beta_{j}}\right] \tilde{r}^{\alpha_{j}}\right\}=\eta_{j} \hat{X}$, where $\hat{X}=21,404$ MWh reflects the average hourly consumption of electricity in Ohio in 2014 (EIA, 2015c). Further suppose the VIP's capacity parameters $\left(a_{K}=16.1\right.$, $\left.b_{K}=0.000674\right)$ ensure that the marginal cost of capacity required to generate a MWh of electricity is approximately 60.4 when $K_{G}=\hat{K}_{G}=32,854$ (MW), which reflects the level of centralized nonrenewable generation capacity in Ohio in 2013 (EIA, 2015c). ${ }^{57}$ Table 3 presents the key elements of the solutions to problems [RPE- $r]$ and $[\mathrm{RPE}-r \mathrm{NM}]$ in this "smaller market" setting.

Four elements of Table 3 warrant emphasis. First, $w$ optimally exceeds $r$ in order to induce substantial investment in DG capacity, which permits reduced electricity production by the VIP's coal-powered generating units. Second, a net metering mandate reduces both $r$ and $w$. The requirement to reduce $w$ to the level at which $r$ is set reduces the DG payments the VIP must make, ceteris paribus. $r$ (and $w$ ) can then be lowered without reducing the VIP's expected profit below zero.

Third, the reduction in $w$ under net metering reduces investment in DG capacity whereas the reduction in $r$ increases electricity demand and associated investment in centralized capacity $\left(K_{G}\right)$. The resulting reduction in the fraction of electricity derived from solar DG causes the social losses from externalities to increase. Fourth, the reduction in $w$ causes consumer $D$ 's expected utility to decline, whereas the reduction in $r$ causes consumer $N$ 's expected utility to increase.

56. The amount of electricity consumed in Ohio is similar to the amount consumed in several other states, including Georgia, Illinois, New York, North Carolina, and Pennsylvania (EIA, 2015c).

57. The estimated cost of capacity required to produce a MWh of electricity using a coal generating unit is $\$ 60.4$ (EIA, 2015a). Much as in the baseline setting, we choose $a_{v}, b_{v}$, and $c_{v}$ to reflect Bushnell (2007)'s estimates for the serving region of the PJM rgional transmission organization (i.e., $a=0$ and $b=0.0009$ ), assuming that the welfare-maximizing level of VIP capacity in the model is $\hat{K}_{G}$. These cost estimates reflect relatively extensive use of coal generating units. 
Parameter values other than those considered here may well be plausible in relevant settings. Consequently, the entries in Tables 2 and 3 are merely illustrative. Nevertheless, these entries demonstrate that the distributional and the aggregate welfare effects of a net metering mandate can be pronounced and can vary substantially with the environment in which the mandate is imposed. The Appendix provides additional illustrations of how the optimal DG compensation policy and industry outcomes vary with prevailing industry conditions in the baseline setting. ${ }^{58}$ These illustrations further support the key qualitative conclusions drawn above.

The Appendix also characterizes outcomes in both the baseline setting and the smaller market setting when the regulator has expanded ability to set a fixed retail charge $(R)$. When the regulator is able to set $R$ to help ensure the utility's solvency, she generally sets $r$ closer to $w$. Consequently, the distributional and aggregate welfare effects of a net metering mandate become less pronounced. ${ }^{59}$

\section{CONCLUSIONS}

We have analyzed the optimal design of compensation for solar distributed generation (DG) of electricity. We found that the optimal unit payment $(w)$ for electricity produced via solar DG reflects the corresponding reductions in the utility's generation, transmission, distribution, and network management costs, and in the social losses from environmental externalities as DG replaces centralized generation of electricity. Furthermore, the optimal retail price of electricity $(r)$ is set in Ramsey fashion to minimize expected weighted deviations between $r$ and the utility's marginal cost of generating electricity.

These optimal values of $w$ and $r$ typically differ. $r$ often exceeds $w$, for instance, when the fixed costs of centralized electricity production and the network management costs of accommodating intermittent solar DG are large, when the marginal cost of centralized generation of electricity varies little with the scale of the utility's operation, and when the social losses from environmental externalities vary little across generating technologies. In contrast, $w$ can exceed $r$ if centralized fixed costs and network management costs associated with intermittent DG production are small, the marginal cost of centralized electricity supply increases rapidly as output increases, and if losses from externalities are substantially lower under DG than under centralized distribution of electricity. Thus, there is no single DG compensation policy that is optimal in all settings. Indeed, the terms of an optimal DG policy, like the effects of a net metering $(w=r)$ mandate, can vary substantially with the prevailing industry characteristics.

We found that as it reduces aggregate welfare, a net metering mandate can produce particularly pronounced distributional effects. Opponents of net metering often argue that a net metering mandate will benefit customers that undertake DG at the expense of those who do not. This may be the case if the relevant benchmark is a policy that provides no compensation for DG production. However, we have shown that this is not necessarily the case if the relevant benchmark is the optimal DG policy. In particular, when the optimal DG policy sets $w$ above $r$, a net metering mandate can cause both $r$ and $w$ to decline. The reduction in $r$ increases the welfare of all consumers. However, the reduction in $w$ can reduce the welfare of those that undertake DG to the point where

58. Brown and Sappington (2016) provide the corresponding analysis for the smaller market setting.

59. In practice, regulators often are reluctant to impose large fixed fees on customers who purchase little electricity, in part because these customers may have limited financial resources. 
their overall level of welfare declines. By discouraging investment in DG capacity, the reduction in $w$ also can increase social losses from externalities.

The optimal DG compensation in our model shares key features with policies like Minnesota's "value of solar" program (Farrell, 2014; Minnesota Department of Commerce, 2014). This program links DG payments to estimated reductions in social losses from environmental externalities and to associated reductions in the utility's generation, transmission, and distribution costs, much as our analysis prescribes. ${ }^{60}$

In concluding, we note six extensions of our model that merit further analysis. First, richer intertemporal structures should be analyzed. When the demand for electricity varies substantially at different times of the day, time-varying retail prices can be structured to limit excess demand. Similarly, time-varying DG compensation can be implemented to better reflect the cost savings that DG production admits at different times of the day.

Second, additional differences among DG consumers merit study. For example, in practice, DG facilities are located at different geographic locations and network congestion costs can vary considerably by geographic region. Therefore, DG compensation might optimally vary by geographic region to reflect relevant variation in the extent to which DG production reduces network congestion costs.

Third, alternative pricing structures warrant consideration. In practice, retail electricity prices often exhibit an increasing block structure whereby the marginal price of electricity increases as electricity consumption increases. Under net metering, this structure can render DG particularly attractive to households that consume large amounts of electricity (Borenstein, 2015). Future research should consider the optimal design of nonlinear retail tariff structures, taking explicit account of how a household's level of electricity consumption can affect its incentive to install solar DG capacity. The role that fixed retail charges can play in alleviating welfare losses from net metering also merits further study. ${ }^{61}$

Fourth, alternative DG technologies should be considered. ${ }^{62}$ The operator can control the amount of electricity produced using some non-solar DG technologies (e.g., combined heat and power units powered by natural gas). The ability to control DG output can engender contracting opportunities that facilitate a utility's load management activities. Because the nature and extent of DG intermittency varies by production technology, the presence of multiple distinct DG technologies may also facilitate load management. Just as the optimal DG policy varies with the characteristics of the single DG source in our model, more generally the optimal DG policy will vary with (and help to determine) the entire range of DG technologies that are employed.

Fifth, alternative regulatory objectives merit consideration. In practice, political pressures can compel regulators to value differently the welfare of different constituents (e.g., those who can

60. Minnesota's program specifies a feed-in tariff that is fixed for 25 years. Our analysis suggests that the optimal DG compensation can vary over time as industry conditions change. However, our analysis does not consider the value of reducing the uncertainty that risk averse consumers face as they consider making substantial investments in long-lived DG capacity. Such considerations merit formal investigation.

61. It has been noted that although fixed retail charges may help to limit welfare losses from a net metering mandate, fixed charges can entail undesirable distributional effects. Consequently, alternative variations on standard retail tariffs (including demand charges) and departures from net metering may better promote regulatory goals (NCCETC, 2014).

62. Future research might also characterize optimal DG compensation policies in settings where household production and consumption of electricity cannot be measured separately. In such settings, net metering will necessarily apply for DG production below consumption, but unit compensation for DG production in excess of consumption can differ from the prevailing unit retail price of electricity. 
readily install DG capacity and those who cannot). ${ }^{63}$ Such differential welfare considerations can affect both the properties of the optimal DG policy and the effects of a net metering mandate. ${ }^{64}$

Sixth, additional policy instruments warrant consideration. ${ }^{65}$ The regulator may be able to secure a higher level of welfare if, for example, she can compensate consumers directly for the DG capacity they install rather than compensate them indirectly through the amount of electricity they produce. An expanded analysis might also permit the regulator to choose the welfare-maximizing level of network reliability. More generally, the optimal design of a DG policy is best viewed as an element of a broader exercise that includes, for example, the optimal design of demand-response, energy conservation, renewable energy portfolio, and network management policies. The optimal coordination of these policies awaits formal investigation.

\section{APPENDIX: ELEMENTS OF THE NUMERICAL SOLUTIONS}

This Appendix further explains the methodology employed to derive the conclusions reported in section 5, illustrates how these conclusions change as parameter values change, and presents additional conclusions.

\section{Solution Methodology}

The key properties of the solutions to [RPE- $r$ ] and [RPE- $r$ NM] are reported in Propositions $\mathrm{A} 1$ and $\mathrm{A} 2$, respectively. ${ }^{6}$ The propositions refer to $\lambda_{1}$ and $\lambda_{2}$, which are the Lagrange multipliers associated with constraint (6) in [RPE-r] and [RPE-rNM], respectively.

Proposition A1. Equation (7) holds at the solution to [RPE-r]. Furthermore:

$$
\begin{gathered}
\lambda_{1} \sum_{j \in\{D, N\}} \int_{\underline{\theta}}^{\bar{\theta}}\left(r-\frac{\partial C^{G}(\cdot)}{\partial Q^{v}}\right) \frac{\partial X^{j}(\cdot)}{\partial r} d F(\theta)-\int_{\underline{\theta}}^{\bar{\theta}} \frac{\partial L(\cdot)}{\partial Q^{v}} \sum_{j \in\{D, N\}} \frac{\partial X^{j}(\cdot)}{\partial r} d F(\theta) \\
+\left[\lambda_{1}-1\right] \sum_{j \in\{D, N\}} \int_{\underline{\theta}}^{\bar{\theta}} X^{j}(\cdot) d F(\theta)=0, \text { and } \\
{\left[1-\lambda_{1}\right] \int_{\underline{\theta}}^{\bar{\theta}} \theta K_{D} d F(\theta)+\frac{\partial K_{D}}{\partial w} \int_{\underline{\theta}}^{\bar{\theta}}\left(\frac{\partial L(\cdot)}{\partial Q^{v}}-\frac{\partial L(\cdot)}{\partial Q^{D}}\right) \theta d F(\theta)} \\
-\lambda_{1}\left[\int_{\underline{\theta}}^{\bar{\theta}}\left(w-\frac{\partial C^{G}(\cdot)}{\partial Q^{v}}\right) \theta d F(\theta)+\frac{\partial T(\cdot)}{\partial K_{D}}\right] \frac{\partial K_{D}}{\partial w}=0 .
\end{gathered}
$$

63. See Cardwell (2012), for example.

64. Regulators are often particularly concerned with the welfare of individuals who find it challenging to pay their utility bills. Future research might explicitly model both this concern and the role that high fixed charges for electricity $(R)$ can play in compelling some customers to exit the distribution network.

65. Alternative prevailing pricing structures also merit investigation. We have examined the impact of net metering mandates when retail electricity prices are set to maximize expected consumer welfare. Net metering mandates can have different effects if they are imposed in settings where prices are not set optimally.

66. The proofs of the propositions presented below parallel the proof of Proposition 2 in Appendix A in Brown and Sappington (2016). 
Proposition A2. Equation (7) holds at the solution to [RPE-rNM]. Furthermore:

$$
\begin{aligned}
\lambda_{2} \sum_{j \in\{D, N\}} \int_{\underline{\theta}}^{\bar{\theta}}\left(r-\frac{\partial C^{G}(\cdot)}{\partial Q^{v}}\right) \frac{\partial X^{j}(\cdot)}{\partial r} d F(\theta)+\left[\lambda_{2}-1\right] \sum_{j \in\{D, N\}} \int_{\underline{\theta}}^{\bar{\theta}} X^{j}(\cdot) d F(\theta) \\
-\int_{\underline{\theta}}^{\bar{\theta}}\left(\frac{\partial L(\cdot)}{\partial Q^{v}} \sum_{j \in\{D, N\}} \frac{\partial X^{j}(\cdot)}{\partial r}-\frac{\partial K_{D}}{\partial r}\left[\frac{\partial L(\cdot)}{\partial Q^{v}}-\frac{\partial L(\cdot)}{\partial Q^{D}}\right] \theta\right) d F(\theta) \\
+\left[1-\lambda_{2}\right] \int_{\underline{\theta}}^{\bar{\theta}} \theta K_{D} d F(\theta)-\lambda_{2}\left[\int_{\underline{\theta}}^{\bar{\theta}}\left(r-\frac{\partial C^{G}(\cdot)}{\partial r}\right) \theta d F(\theta)+\frac{\partial T(\cdot)}{\partial K_{D}}\right] \frac{\partial K_{D}}{\partial r}=0 .
\end{aligned}
$$

Propositions A1 and A2 identify the necessary conditions for solutions to the relevant problems. Mathematica and the Newton-Raphson Iteration Method are employed solve the conditions (and constraint (6)) for the optimal values of $r, w$, and $K_{D}$, given the specified functional forms and parameter values.

\section{Sensitivity Analysis}

We now illustrate how the outcomes in the baseline setting analyzed in section 5 change as key parameter values change. Figures A1-A15 report the effects of changes in the VIP's variable production cost $\left(b_{v}\right)$, the VIP's capacity costs $\left(b_{K}\right)$, DG capacity costs $\left(b_{D}\right)$, the VIP's TDM costs $\left(a_{T}^{D}\right)$ costs, and the losses from environmental externalities $\left(e_{v}\right)$ associated with centralized electricity production. In each figure, parameters other than the one being varied are fixed at the levels identified in the baseline setting. Furthermore, "(NM)" denotes the relevant variable under a net metering mandate (which requires $w=r$ ). Variables without the "(NM)" designation denote variables under the optimal policy when no net metering mandate is imposed.

The Effects of Changes in the VIP's Variable Production Cost $\left(b_{v}\right)$

Figure A1: Impact of Changes in $b_{v}$ on Retail Electricity Prices and DG Compensation

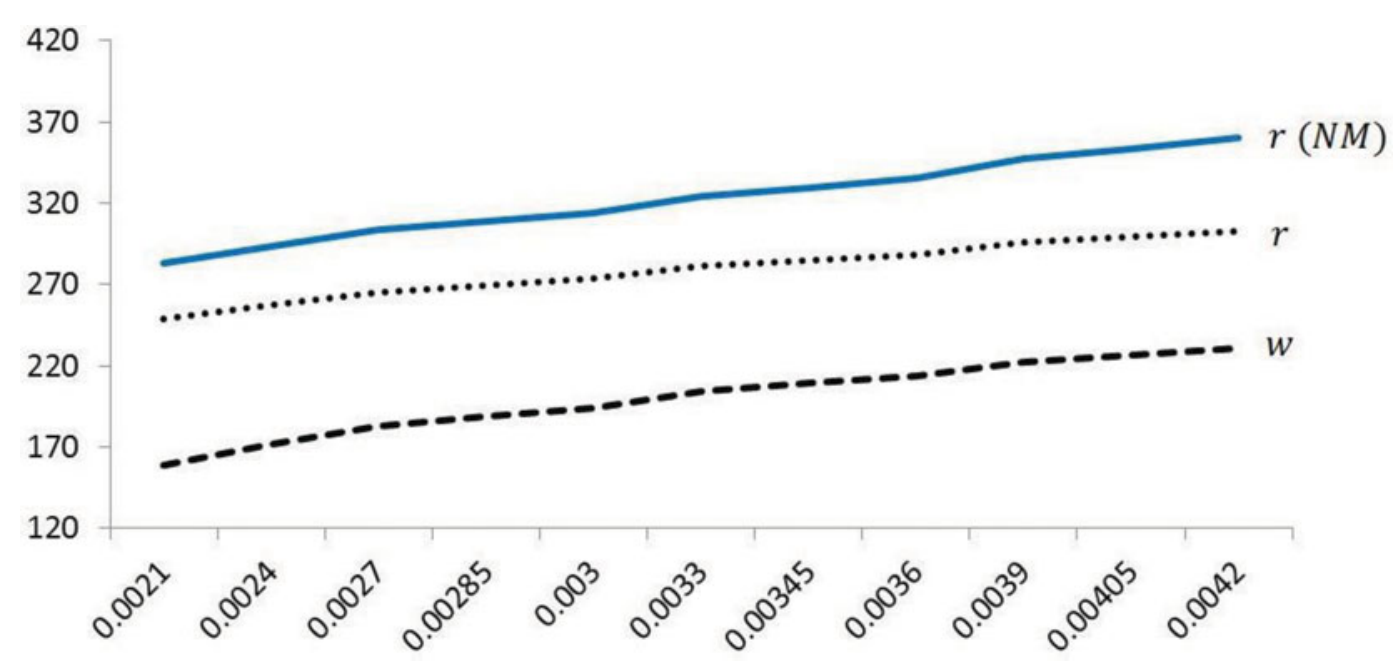




\section{Figure A2: Impact of Changes in $b_{v}$ on Capacity Investments}

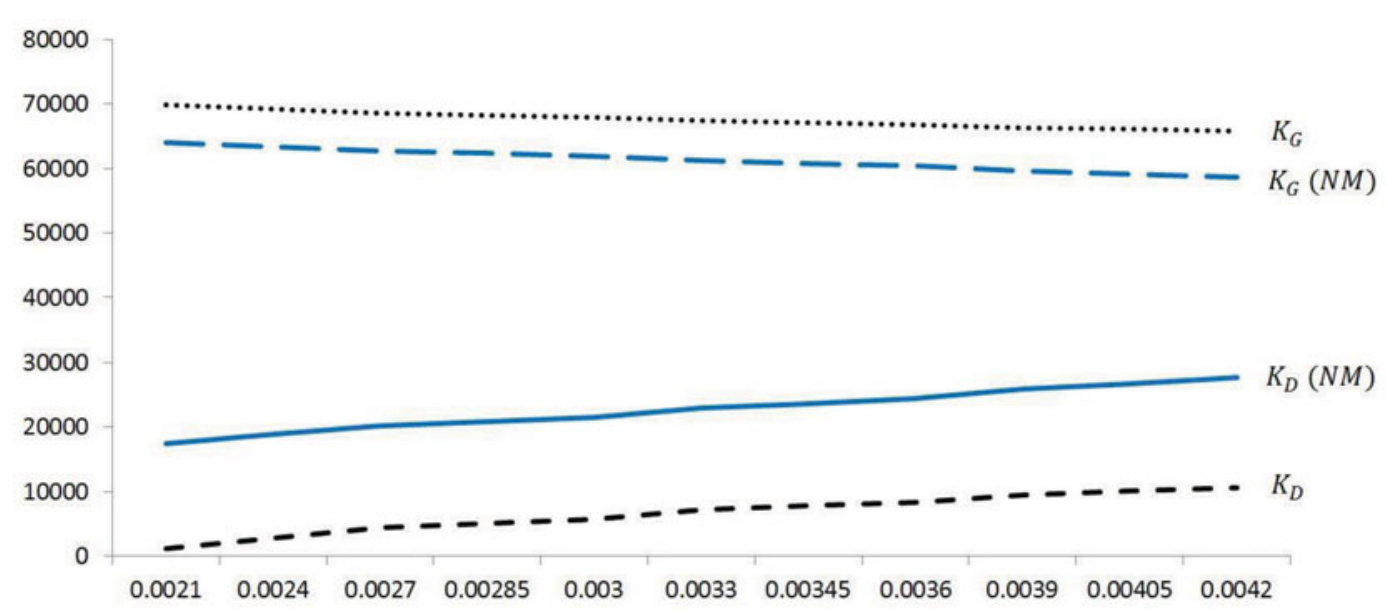

Figure A3: Impact of Changes in $b_{v}$ on Consumer Welfare

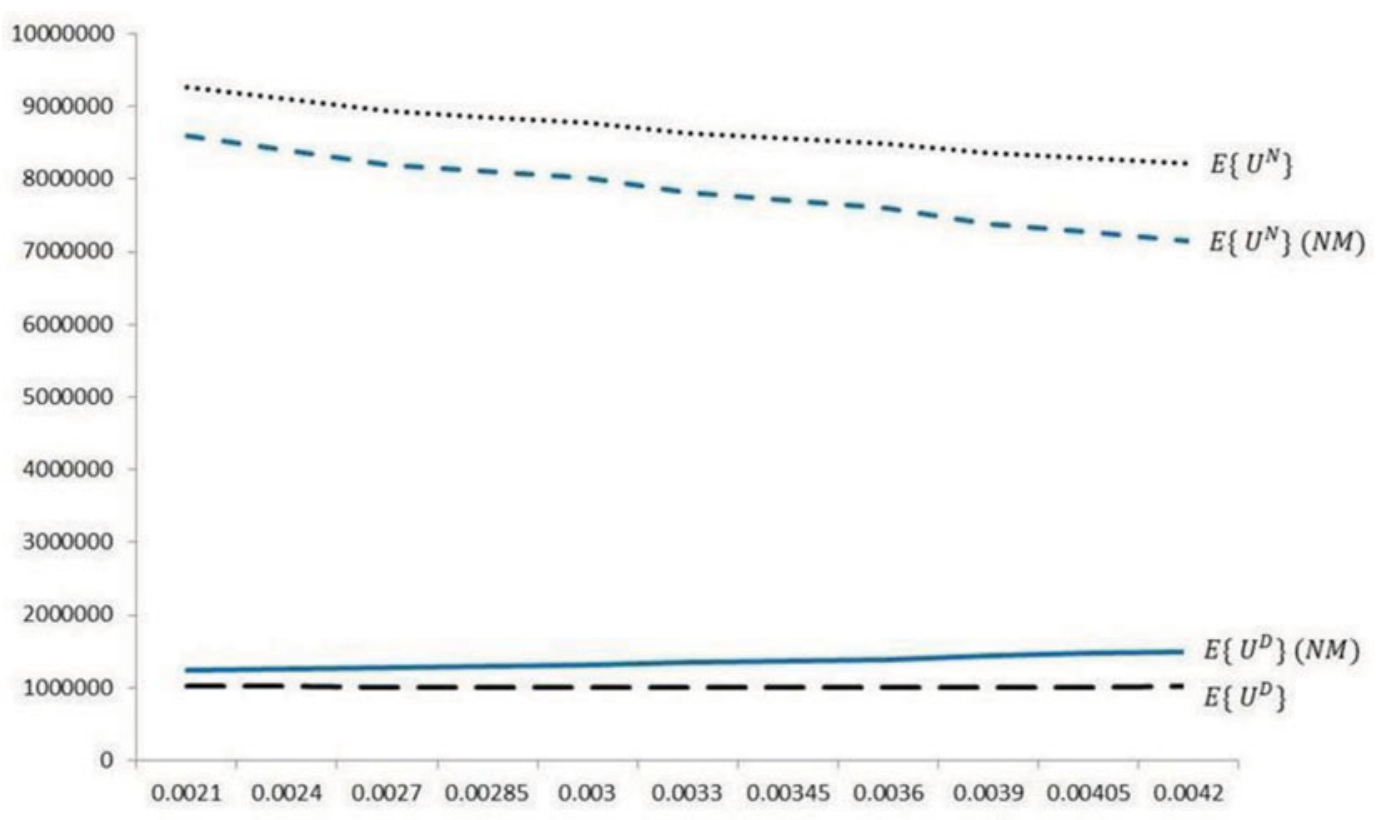

As the VIP's variable cost $\left(b_{v}\right)$ increases, the value of a unit of solar DG capacity increases. The regulator increases $w$ to induce increased investment in DG capacity. $r$ also increases in light of the increased marginal cost of generating electricity. The net metering mandate systematically serves to increase the unit price of electricity (and the unit DG compensation) above the values of $r$ and $w$ that prevail in the absence of the mandate. $K_{G}$ declines as $b_{v}$ increases because the VIP produces less output as its variable cost increases. The welfare of consumer $N$ declines due to the increase in $r$, whereas the welfare of consumer $D$ increases due to the increase in $w$. 
The Effects of Changes in the Cost of Centralized Capacity $\left(b_{K}\right)$

Figure A4: Impact of Changes in $b_{v}$ on Retail Electricity Prices and DG Compensation

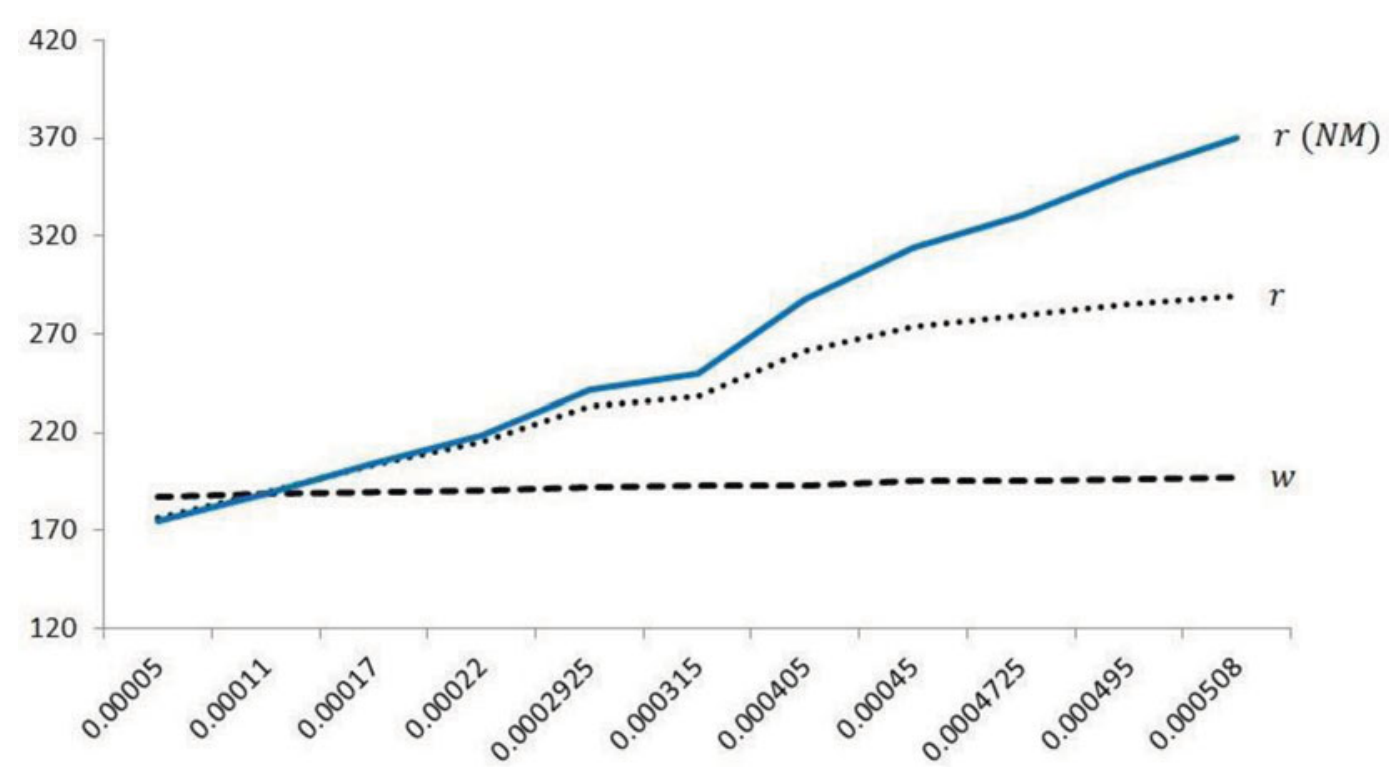

Figure A5: Impact of Changes in $b_{v}$ on Capacity Investments

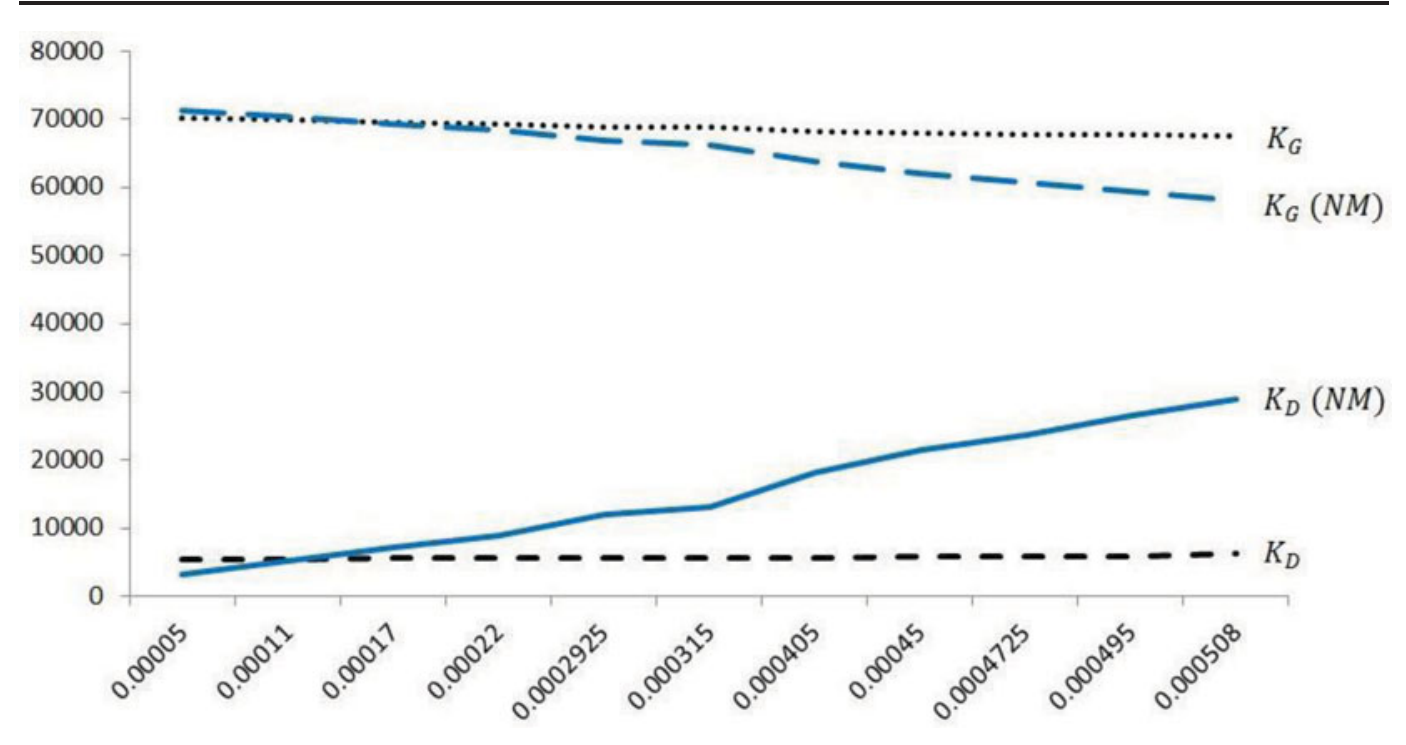




\section{Figure A6: Impact of Changes in $b_{K}$ on Consumer Welfare}

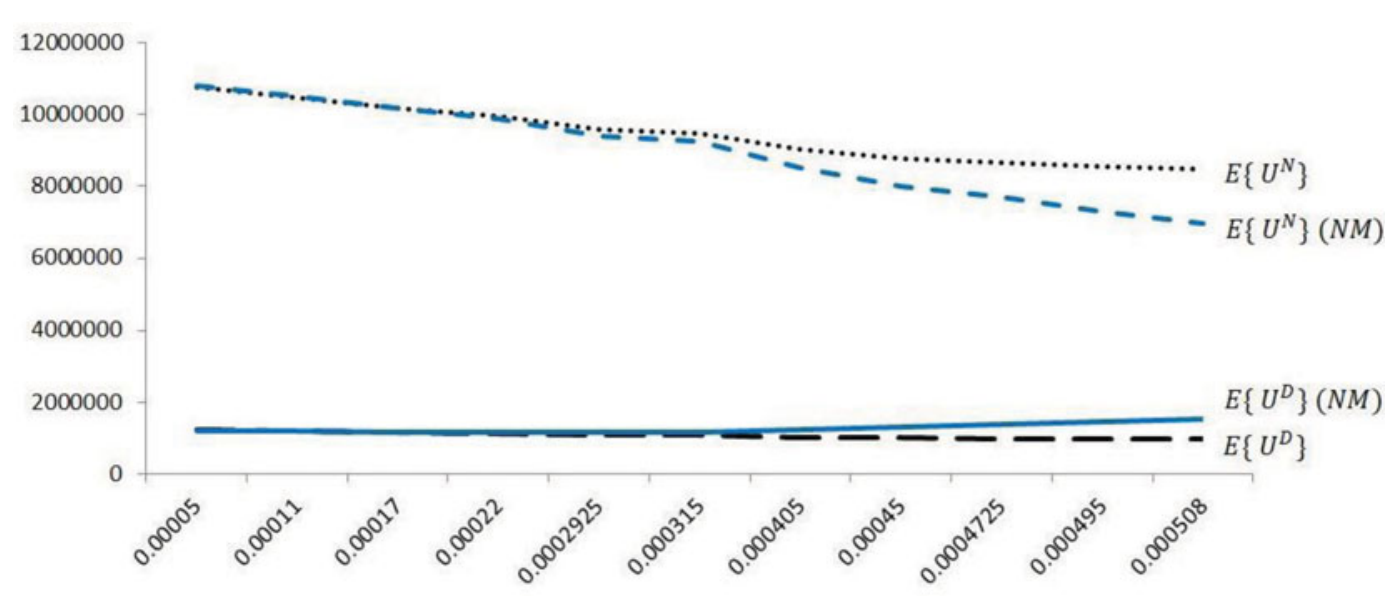

As the cost of centralized capacity $\left(b_{k}\right)$ increases, $r$ is increased to ensure the VIP's solvency despite its increased operating costs. The welfare of consumer $N$ declines due to the increase in $r$. A net metering mandate increases the impact of changes in $b_{K}$ on $K_{D}$ and $K_{G}$ because the regulator has one fewer instruments to control investment choices. Under a net metering mandate, $r$ and $w$ increase relatively rapidly as $b_{k}$ increases, which reduces consumer $N$ 's welfare and increases consumer $D$ 's welfare.

The Effects of Changes in the Cost of DG Capacity $\left(b_{D}\right)$

\section{Figure A7: Impact of Changes in $b_{D}$ on Retail Electricity Prices and DG Compensation}

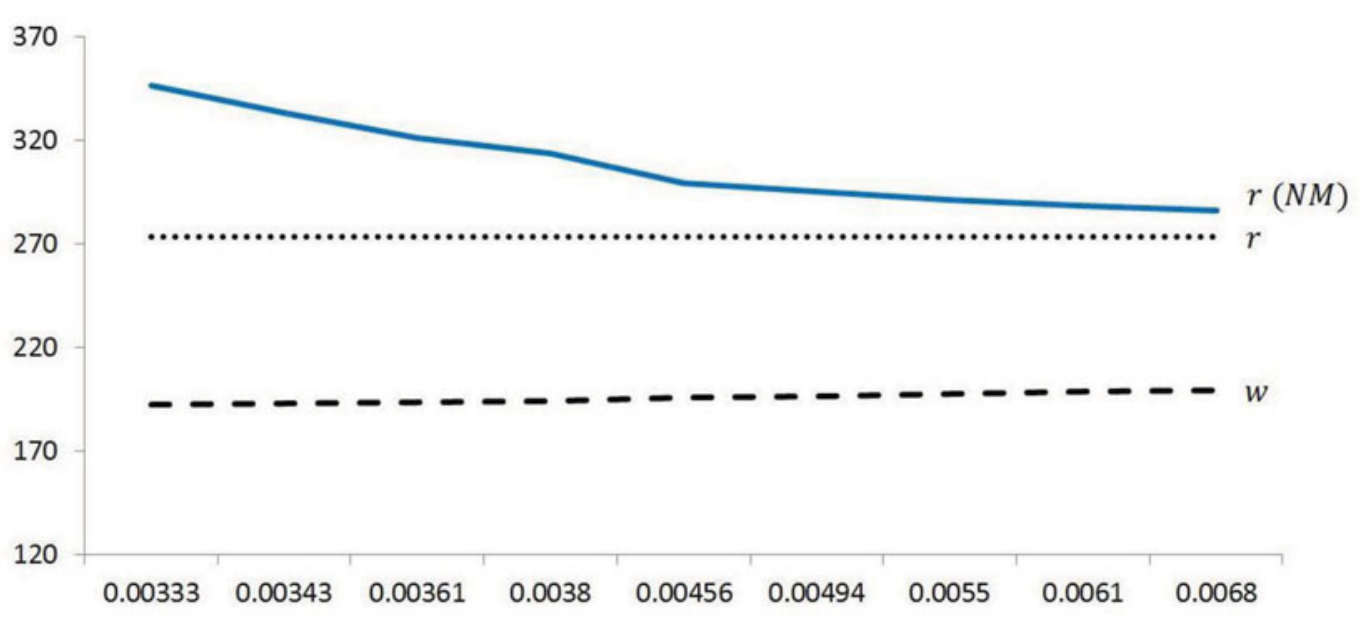


Figure A8: Impact of Changes in $b_{D}$ on Capacity Investments

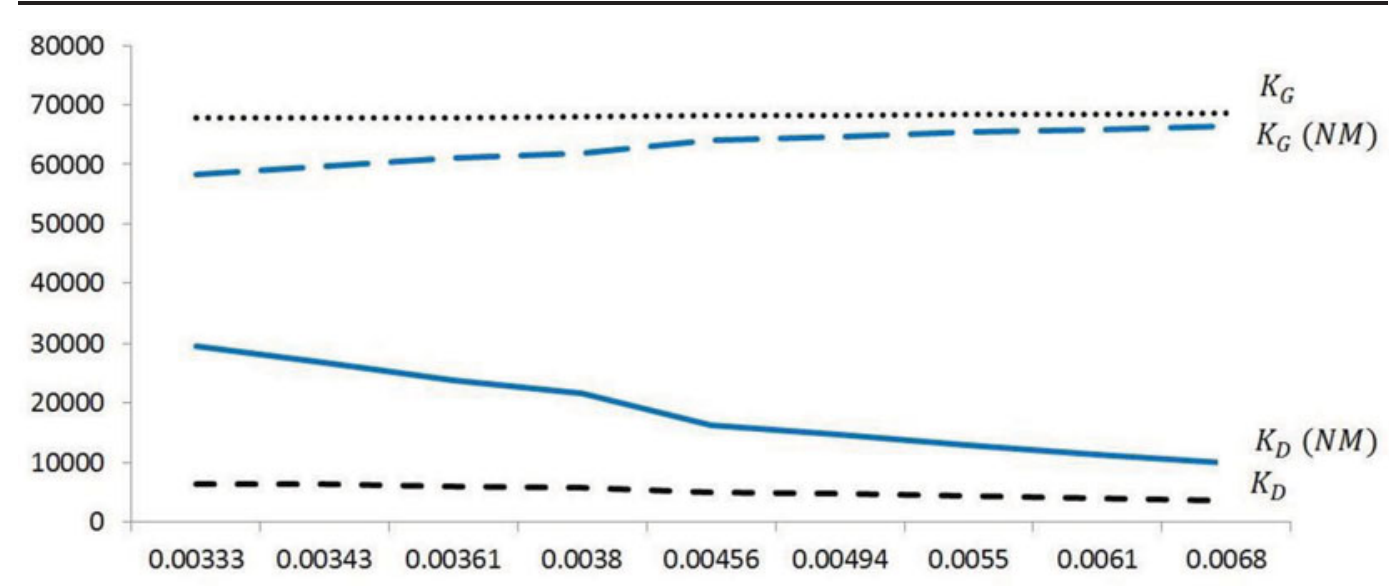

Figure A9: Impact of Changes in $b_{D}$ on Consumer Welfare

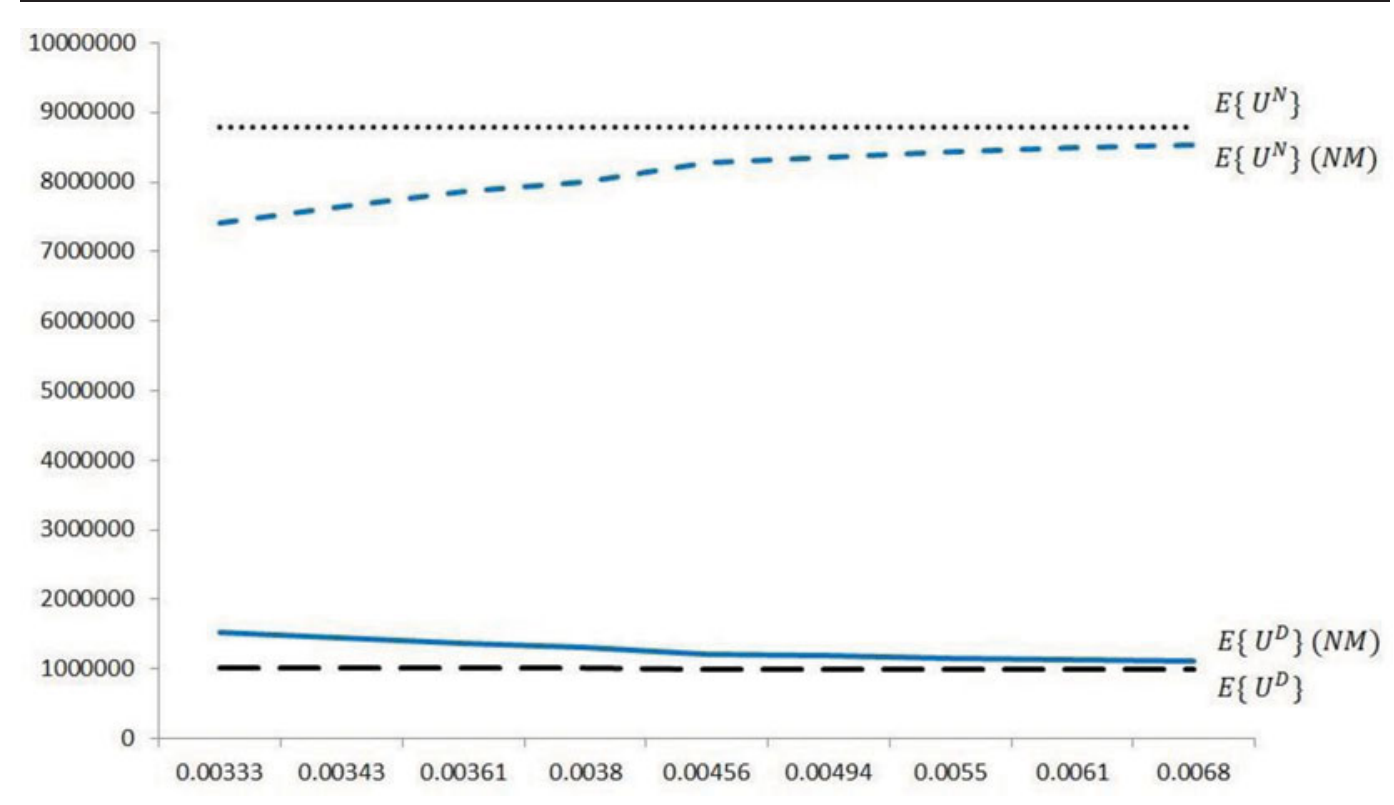

As the cost of DG capacity $\left(b_{D}\right)$ increases, the amount of DG capacity investment $\left(K_{D}\right)$ decreases and the amount of centralized capacity $\left(K_{G}\right)$ increases. The reduction in $K_{D}$ arises despite an increase in $w$ which is implemented to avoid an excessive reduction in DG capacity investment as its cost increases. Under a net metering mandate, $r$ and $w$ decline as $b_{D}$ increases, causing consumer $N$ 's welfare to increase and consumer $D$ 's welfare to decline. 
The Effects of Changes in TDM Costs $\left(\alpha_{T}^{D}\right)$

Figure A10: Impact of Changes in $\alpha_{T}^{D}$ on Retail Electricity Prices and DG Compensation

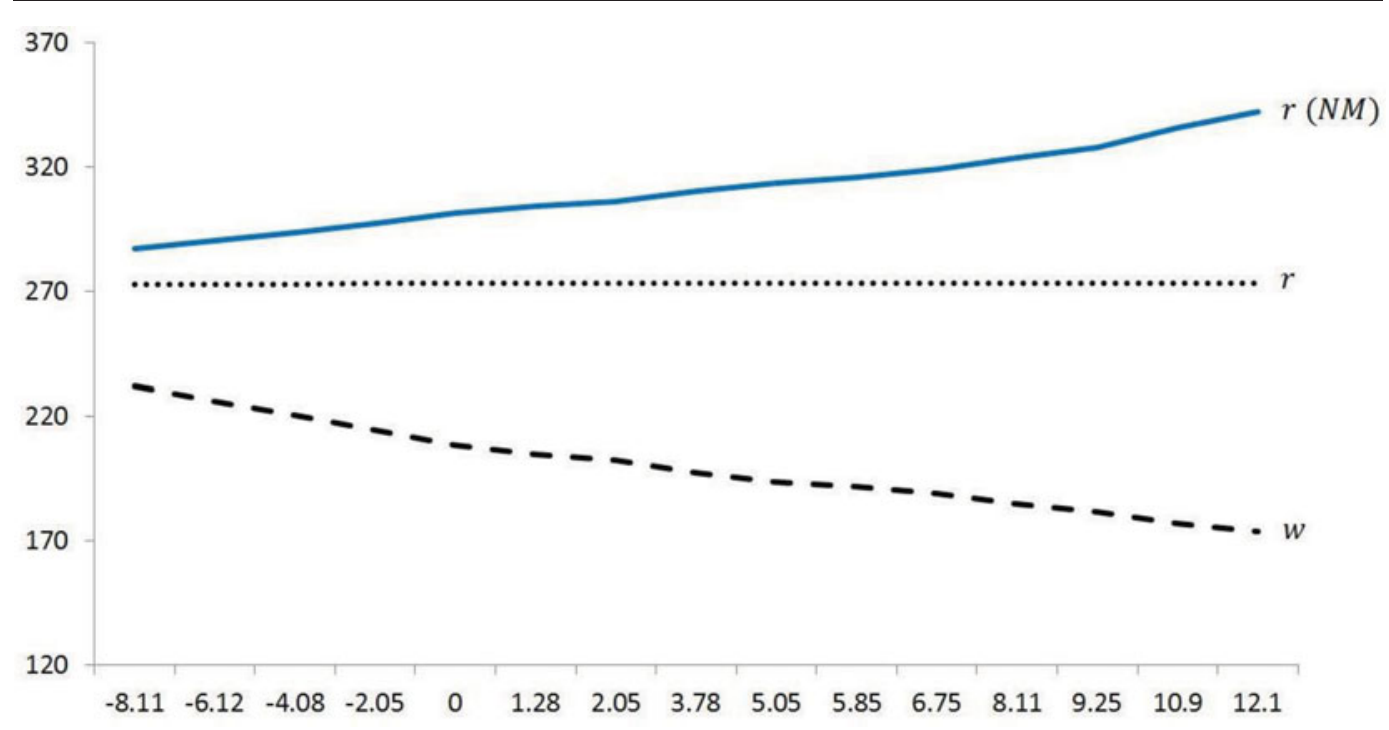

Figure A11: Impact of Changes in $\alpha_{T}^{D}$ on Capacity Investments

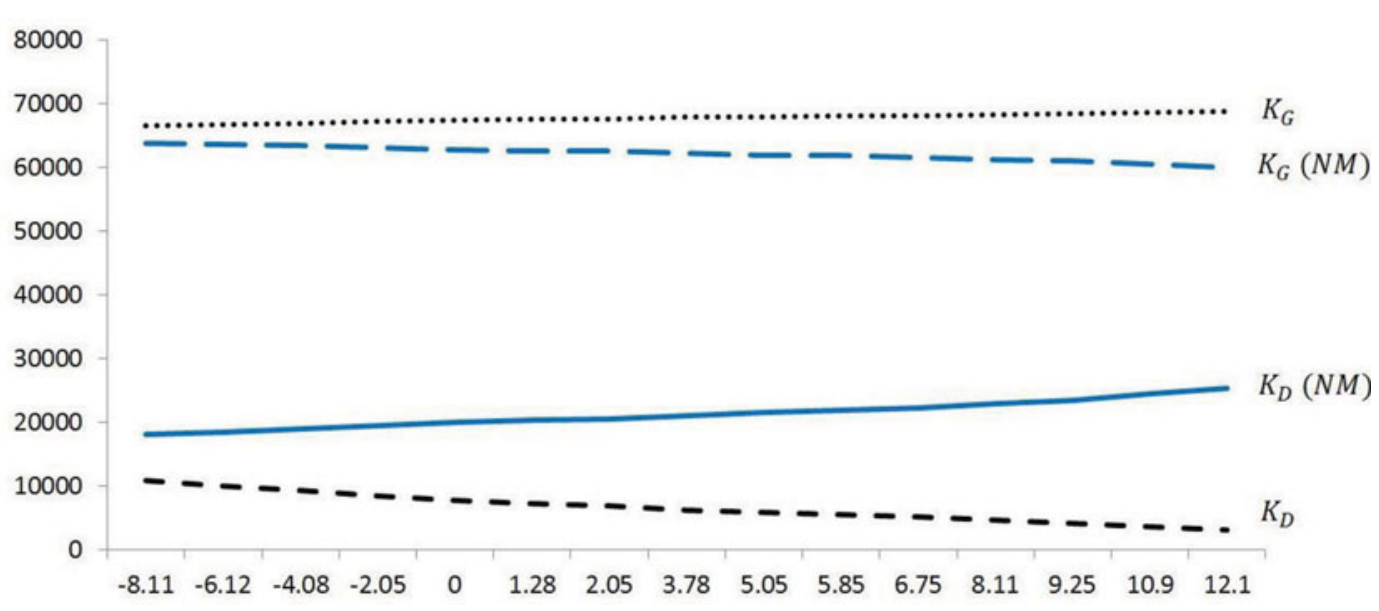




\section{Figure A12: Impact of Changes in $\alpha_{T}^{D}$ on Consumer Welfare}

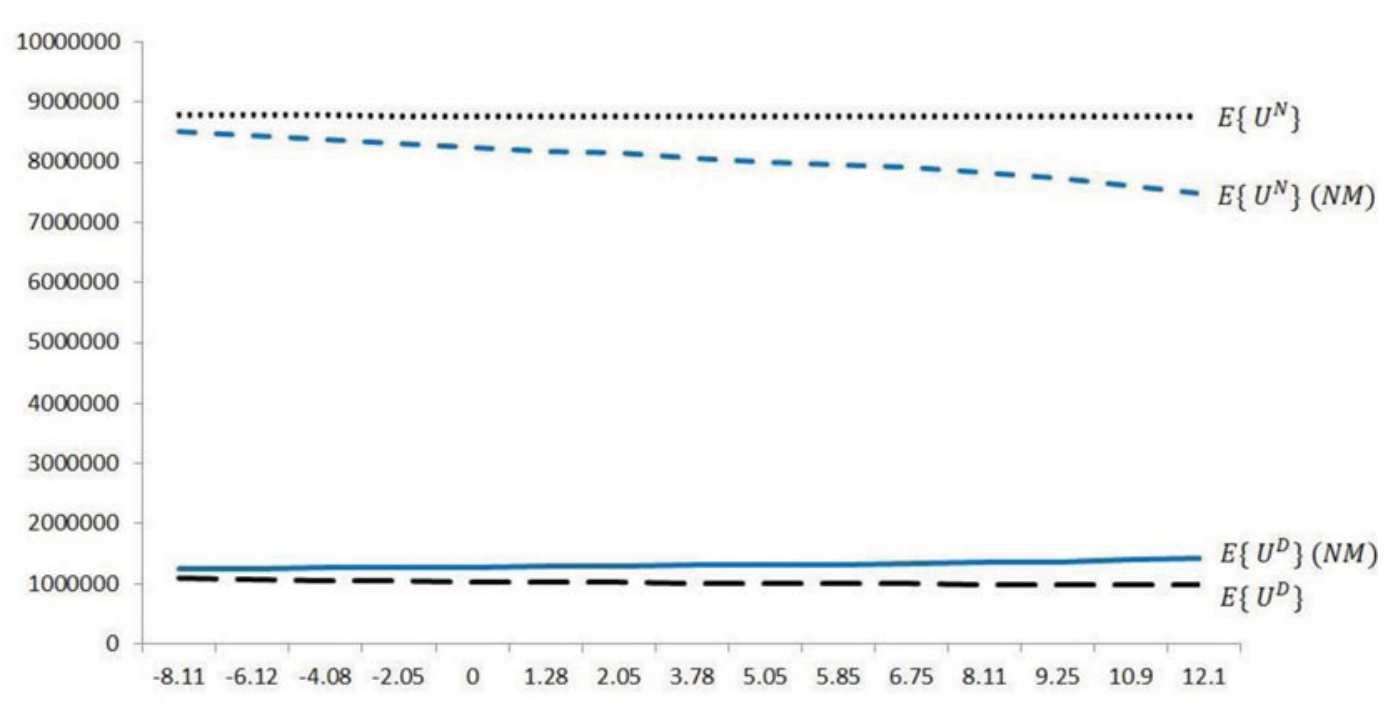

As TDM costs increase, $w$ is reduced to induce less investment in DG capacity. Centralized capacity is increased as DG capacity declines. The increase in the retail price of electricity induced by a net metering mandate becomes more pronounced as TDM costs increase. The increase in $r$ and $w$ under net metering causes welfare of consumer $N$ to decline and the welfare of consumer $D$ to increase.

The Effects of Changes in Marginal Losses from Environmental Externalities $\left(e_{v}\right)$

\section{Figure A13: Impact of Changes in $e_{v}$ on Retail Electricity Prices and DG Compensation}

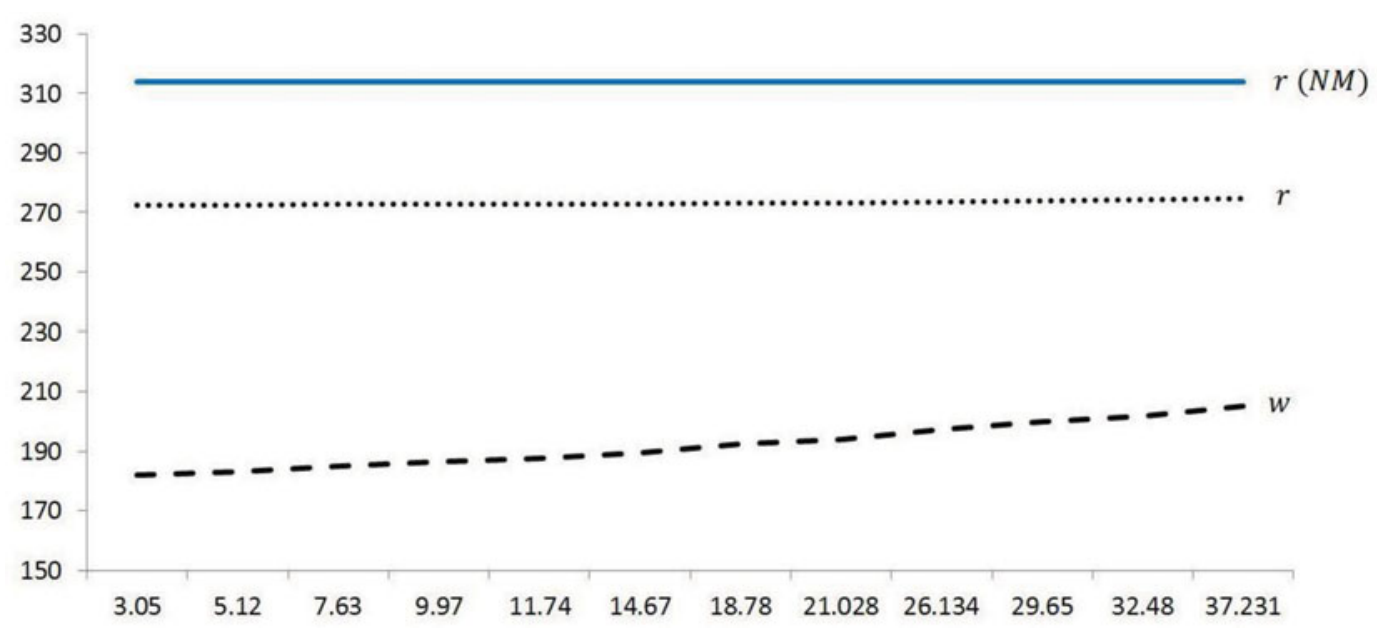


Figure A14: Impact of Changes in $e_{v}$ on Capacity Investments

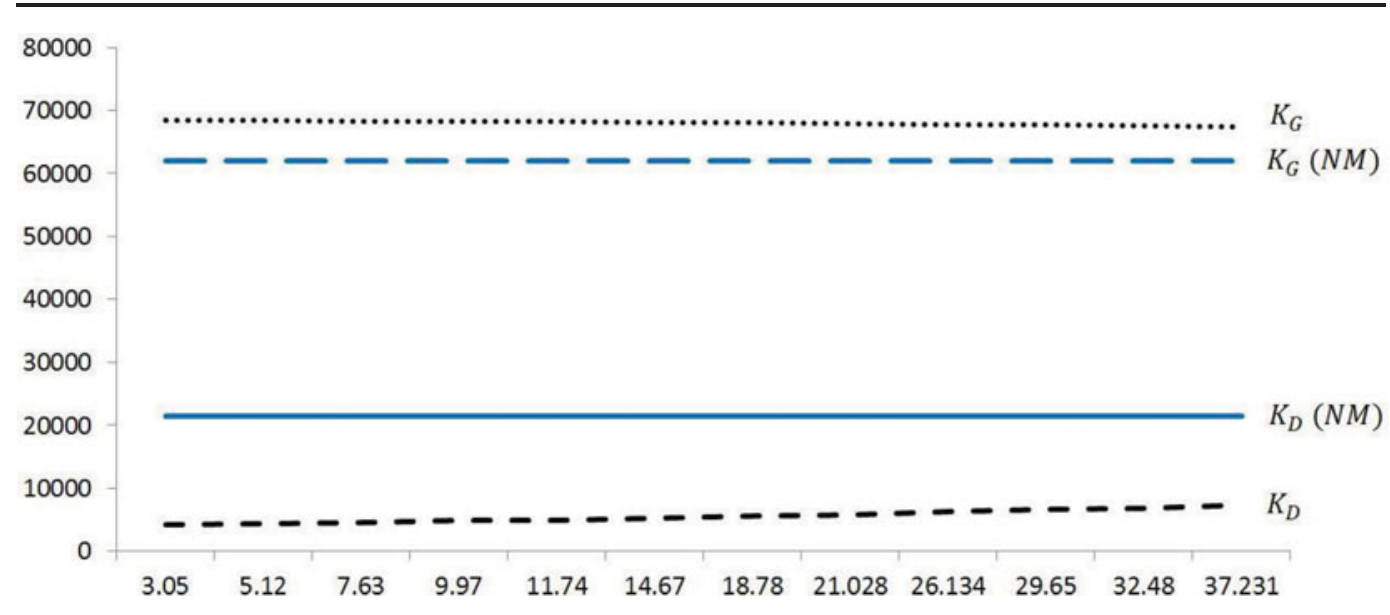

Figure A15: Impact of Changes in $e_{v}$ on Consumer Welfare

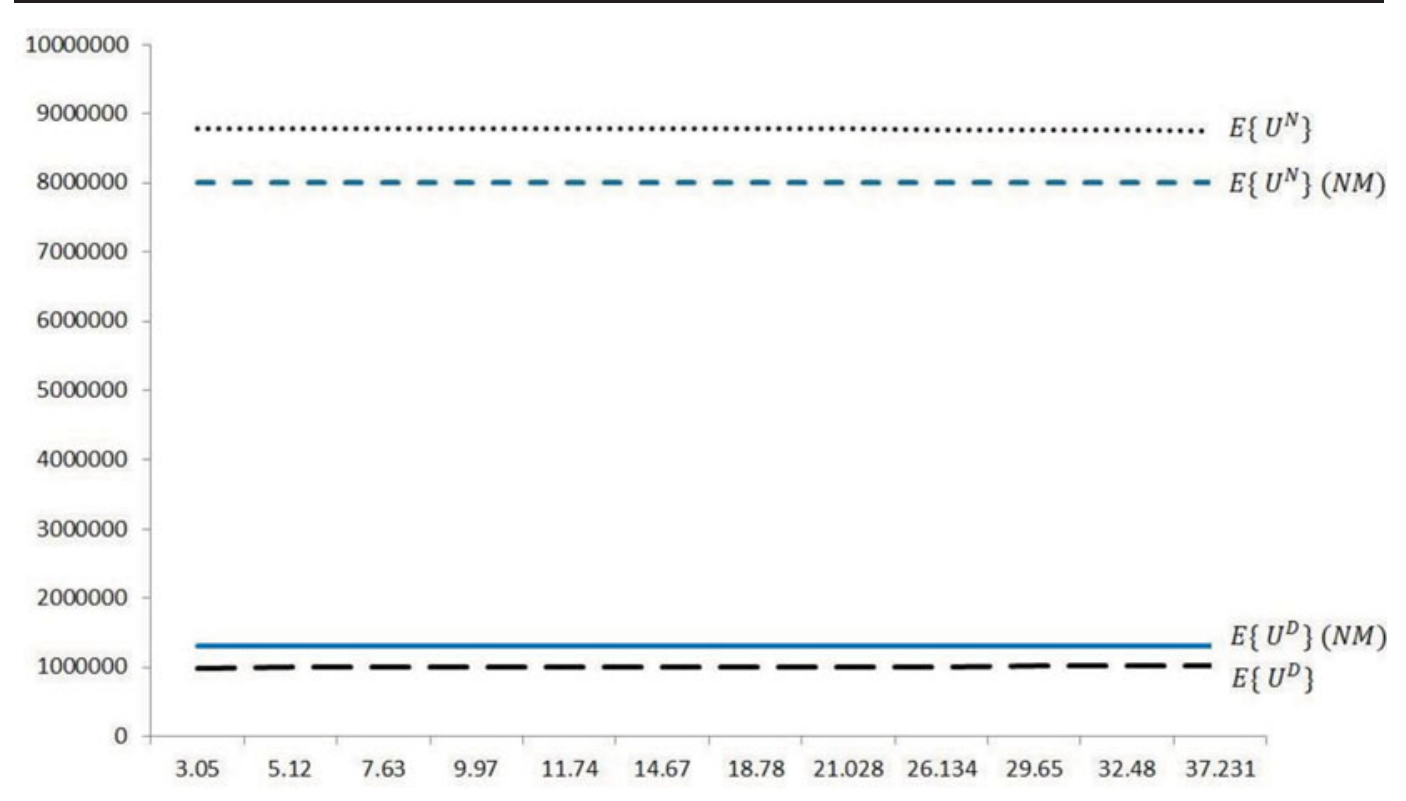

As the marginal social loss due to environmental externalities from centralized production $\left(e_{v}\right)$ increases, $r$ is increased to reduce consumption and $w$ is increased to induce increased DG production. A net metering mandate increases both $r$ and $w$, and renders these (constrained) policy instruments relatively insensitive to changes in $e_{v}$. 


\section{The Effects of a Fixed Retail Charge}

The impact of a net metering mandate can be less pronounced when the regulator is able to set a fixed retail charge $(R)$ that does not affect the demand for electricity. ${ }^{67}$ The difference between the optimal values of $w$ and $r$ often is reduced when the regulator can employ a fixed retail charge to recover the VIP's fixed production costs (without inducing any customers to reduce their electricity consumption to zero). Consequently, a mandate to set identical values for $w$ and $r$ can be less constraining. To illustrate this point, consider the solutions to problems [RP] and [RP-NM] in the baseline setting. The latter problem is problem [RP] with the additional constraint that $w=$ $r$.

Proposition A3. Equations (7) and (10) hold at the solution to [RP-NM]. Furthermore:

$$
\begin{aligned}
& \sum_{j \in\{D, N\}} \int_{\underline{\theta}}^{\bar{\theta}}\left[r-\left(\frac{\partial C^{G}(\cdot)}{\partial Q^{v}}+\frac{\partial L(\cdot)}{\partial Q^{v}}\right)\right] \frac{\partial X^{j}}{\partial r} d F(\theta) \\
& -\left[\int_{\underline{\theta}}^{\bar{\theta}}\left(r-\left[\frac{\partial C^{G}(\cdot)}{\partial Q^{v}}+\frac{\partial L(\cdot)}{\partial Q^{v}}-\frac{\partial L(\cdot)}{\partial Q^{D}}\right]\right) \theta d F(\theta)+\frac{\partial T(\cdot)}{\partial K_{D}}\right] \frac{\partial K_{D}}{\partial r}=0 .
\end{aligned}
$$

Table A1 records the key outcomes at the solutions to problems [RP] and [RP-NM] in the baseline setting. Table A2 presents the corresponding outcomes in the smaller market setting. The tables indicate that a net metering $(w=r)$ mandate can be substantially less constraining when the regulator has unfettered ability to set a fixed retail charge that does not affect consumer demand for electricity.

Table A1: Outcomes in the Baseline Setting with an Unrestricted Fixed Retail Charge

\begin{tabular}{|l|c|c|c|r|r|c|c|c|}
\hline Problem & $r$ & $w$ & $K_{G}$ & $K_{D}$ & $E\left\{U^{N}\right\}$ & $E\left\{U^{D}\right\}$ & $E\{L\}$ & $E\{W\}$ \\
\hline$[\mathrm{RP}]$ & 203.4 & 201.4 & 69,660 & 6,764 & $8,846.8$ & $1,025.2$ & 455.1 & $9,417.0$ \\
\hline [RP-NM] & 202.3 & 202.3 & 69,667 & 6,874 & $8,845.7$ & $1,026.5$ & 455.2 & $9,417.0$ \\
\hline
\end{tabular}

Table A2: Outcomes in the Smaller Market Setting with an Unrestricted Fixed Retail Charge

\begin{tabular}{|l|c|c|c|r|c|c|c|l|}
\hline Problem & $r$ & $w$ & $K_{G}$ & $K_{D}$ & $E\left\{U^{N}\right\}$ & $E\left\{U^{D}\right\}$ & $E\{L\}$ & $E\{W\}$ \\
\hline$[\mathrm{RP}]$ & 194.5 & 195.8 & 32,205 & 6,023 & $9,333.9$ & $1,070.6$ & 386.6 & $10,017.9$ \\
\hline [RP-NM] & 195.3 & 195.3 & 32,202 & 5,960 & $9,334.4$ & $1,069.9$ & 386.5 & $10,017.9$ \\
\hline
\end{tabular}

In practice, regulators often are reluctant to impose large fixed fees on customers who purchase little electricity (perhaps in part because these customers often have limited financial resources). The analysis in the text considers the case where this reluctance leads the regulator to impose no fixed retail charge. Tables A3 and and A4 report the outcomes that arise when the

67. Faruqui and Hledik (2015), among others, stress the importance of implementing fixed retail charges that reflect the utility's fixed production costs. 
regulator sets the fixed retail charge at one-half of its optimal value. The tables refer to $[\mathrm{NM}-R / 2]$ and $[\mathrm{RP}-R / 2]$ which, respectively, denote the regulator's problem in this setting when a net metering mandate is, and is not, imposed.

Table A3: Outcomes in the Baseline Setting with a Restricted Fixed Retail Charge

\begin{tabular}{|c|c|c|c|c|c|c|c|c|}
\hline Problem & $r$ & $w$ & $K_{G}$ & $K_{D}$ & $E\left\{U^{N}\right\}$ & $E\left\{U^{D}\right\}$ & $E\{L\}$ & $E\{W\}$ \\
\hline$[\mathrm{RP}-R / 2]$ & 237.1 & 197.2 & 68,788 & 6,212 & $8,825.1$ & $1,016.2$ & 439.5 & $9,401.9$ \\
\hline$[\mathrm{NM}-\mathrm{R} / 2]$ & 245.5 & 245.5 & 66,663 & 12,571 & $8,643.3$ & $1,106.2$ & 402.9 & $9,346.6$ \\
\hline
\end{tabular}

Table A4: Outcomes in the Smaller Market Setting with a Restricted Fixed Retail Charge

\begin{tabular}{|c|c|c|c|r|c|c|c|l|}
\hline Problem & $r$ & $w$ & $K_{G}$ & $K_{D}$ & $E\left\{U^{N}\right\}$ & $E\left\{U^{D}\right\}$ & $E\{L\}$ & $E\{W\}$ \\
\hline$[\mathrm{RP}-R / 2]$ & 178.4 & 199.3 & 32,411 & 6,491 & $9,331.4$ & $1,075.7$ & 393.3 & $10,013.8$ \\
\hline$[\mathrm{NM}-\mathrm{R} / 2]$ & 177.3 & 177.3 & 32,876 & 3,593 & $9,358.5$ & $1,051.7$ & 408.8 & $10,001.5$ \\
\hline
\end{tabular}

Tables A3 and A4 report welfare losses from a net metering mandate that are intermediate between the losses the mandate imposes when fixed retail tariffs are prohibited and when no limits are placed on these tariffs.

\section{ACKNOWLEDGMENTS}

We thank the editor, three anonymous referees, Hung-po Chao, Thomas Lyon, Paul Sotkiewicz, Xuejuan Su, Burcin Unel, and conference participants for helpful comments and suggestions. An earlier version of the paper was entitled "On the Design of Distributed Generation Policies: Are Common Net Metering Policies Optimal?"

\section{REFERENCES}

American Council for an Energy-Efficient Economy (2014). Distributed Generation (http://www.aceee.org/topics/distributed-generation), visited September 21, 2014.

American Public Power Association (2013). Distributed Generation: An Overview of Recent Policy and Market Developments, Washington, DC (http://www.publicpower.org/files/PDFs/Distributed\%20Generation-Nov2013.pdf).

Baumol, W. and D. Bradford (1970). "Optimal Departures from Marginal Cost Pricing.” American Economic Review 60(3): 265-283.

Bernstein, M. and J. Griffin (2006). "Regional Differences in the Price-Elasticity of Demand for Energy." Rand Corporation Report NREL/SR-620-39512 prepared for the National Renewable Energy Laboratory (http://www.nrel.gov/docs/ fy06osti/39512.pdf). http://dx.doi.org/10.2172/877655.

Bohi, D. and M.B. Zimmerman (1984). “An Update on Econometric Studies of Energy Demand Behavior.” Annual Review of Energy 9: 105-154. http://dx.doi.org/10.1146/annurev.eg.09.110184.000541.

Borenstein, S. (2014). "What's So Great about Fixed Charges?" Energy Institute at Haas (https://energyathaas.wordpress.com/2014/11/03/whats-so-great-about-fixed-charges).

Borenstein, S. (2015). "Private Net Benefits of Residential Solar PV: The Role of Electricity Tariffs, Tax Incentives, and Rebates.” UC Berkeley Working Paper Series (http://ei.haas.berkeley.edu/research/papers/WP259.pdf). http://dx.doi.org/ $10.3386 / \mathrm{w} 21342$. 
Branker, K., M. Pathak, and J. Pearce. (2011). “A Review of Solar Photovoltaic Levelized Cost of Electricity.” Renewable and Sustainable Energy Reviews 15(9): 4470-4482. http://dx.doi.org/10.1016/j.rser.2011.07.104.

Brown, D. and D. Sappington. (2016) "Technical Appendix to Accompany 'Designing Compensation for Distributed Solar Generation: Is Net Metering Ever Optimal?’.” (https://uofa.ualberta.ca/arts/about/people-collection/david-brown).

Bushnell, J. (2007). "Oligopoly Equilibria in Electricity Contract Markets.” Journal of Regulatory Economics 32(3): 225245. http://dx.doi.org/10.1007/s11149-007-9031-2.

Bushnell, J., E. Mansur, and C. Saravia. (2008). "Vertical Arrangements, Market Structure, and Competition: An Analysis of Restructured US Electricity Markets." American Economic Review 98(1): 237-266. http://dx.doi.org/10.1257/ aer.98.1.237.

California Energy Commission (2015). "Electricity Generation Capacity \& Energy." California Energy Almanac (http:// energyalmanac.ca.gov/electricity/electric_generation_capacity.html), visited September 10, 2015.

California Independent System Operator (2015a). Open Access Same-time Information System (http://oasis.caiso.com), visited September 15, 2015.

California Independent System Operator (2015b). Renewables Watch: Reports and Data (http://www.caiso.com/market/ Pages/ReportsBulletins/DailyRenewablesWatch.aspx).

California Public Utilities Commission (2015). Utility Tariff Information (http://www.cpuc.ca.gov/PUC/energy/Electric + Rates/utiltariffs/index.htm), visited October 12, 2015.

California Solar Statistics (2015). Geographical Statistics (https://www.californiasolarstatistics.ca.gov/reports/locale_stats), visited September 10, 2015.

Cardwell, D. (2012). "Solar Panel Payments Set Off a Fairness Debate.” The New York Times, June 4 (http:// www.nytimes.com/2012/06/05/business/solar-payments-set-off-a-fairness-debate.html?_r = 0).

Cohen, M., P. Kauzmann, and D. Callaway (2015). "Economic Effects of Distributed PV Generation on California's Distribution System.” Energy Institute at Haas Working Paper 260 (http://ei.haas.berkeley.edu/research/papers/WP260.pdf).

Couture, T. and Y. Gagnon (2010). "An Analysis of Feed-in Tariff Remuneration Models: Implications for Renewable Energy Investment.” Energy Policy 38(2): 955-965. http://dx.doi.org/10.1016/j.enpol.2009.10.047.

Darghouth, N., G. Barbose, and R. Wiser (2011). "The Impact of Rate Design and Net Metering on the Bill Savings from Distributed PV for Residential Customers in California.” Energy Policy 39(9): 5243-5253. http://dx.doi.org/10.1016/ j.enpol.2011.05.040.

Darghouth, N., G. Barbose, and R. Wiser (2014). "Customer-Economics of Residential Photovoltaic Systems (Part 1): The Impact of High Renewable Energy Penetrations on Electricity Bill Savings with Net Metering.” Energy Policy 67: 290 300. http://dx.doi.org/10.1016/j.enpol.2013.12.042.

Eid, C., J.R. Guillén, P.F. Marn, and R. Hakvoort (2014). "The Economic Effect of Electricity Net-Metering with Solar PV: Consequences for Network Cost Recovery, Cross Subsidies and Policy Objectives.” Energy Policy 75: 244-254. http:// dx.doi.org/10.1016/j.enpol.2014.09.011.

Espey, J. and M. Espey (2004). "Turning on the Lights: A Meta-Analysis of Residential Electricity Demand Elasticities." Journal of Agricultural and Applied Economics 36(1): 65-81. http://dx.doi.org/10.1017/S1074070800021866.

Farrell, J. (2014). “Minnesota's Value of Solar: Can a Northern State's New Solar Policy Defuse Distributed Generation Battles?” Institute for Local Self-Reliance Report (http:// www.ilsr.org/wp-content/uploads/2014/04/MN-Value-of-Solarfrom-ILSR.pdf).

Faruqui, A. and R. Hledik (2015). “An Evaluation of SRP's Electric Rate Proposal for Residential Customers with Distributed Generation.” The Brattle Group Report Prepared for Salt River Project (http://www.srpnet.com/prices/priceprocess/ pdfx/DGRateReview. pdf).

Gordon, K., W. Olson, and A. Nieto (2006). "Responding to EPAct 2005: Looking at Smart Meters for Electricity, TimeBased Rate Structures, and Net Metering." Report prepared for the Edison Electric Institute (http://sites.energetics.com/ MADRI/pdfs/responding_to_epact.pdf).

Institute for Electric Efficiency (2014). Utility-Scale Smart Meter Deployments, Building Block of the Evolving Power Grid (http://www.edisonfoundation.net/iei/Documents/IEI_SmartMeterUpdate_0914.pdf).

Ito, K. (2014). "Do Consumers Respond to Marginal or Average Price? Evidence from Nonlinear Electricity Pricing." American Economic Review 104(2): 537-563. http://dx.doi.org/10.1257/aer.104.2.537.

Kind, P. (2013). "Disruptive Challenges: Financial Implications and Strategic Responses to a Changing Retail Electric Business." Report prepared for the Edison Electric Institute (http://www.eei.org/ourissues/finance/Documents/disruptivechallenges.pdf).

King, C. and S. Chatterjee (2003). "Predicting California Demand Response: How do Consumers React to Hourly Price?" Public Utilities Fortnightly 141(13): 27-32. 
Kuang, H., S. Li, and Z. Wu (2011). "Discussion on Advantages and Disadvantages of Distributed Generation Connected to the Grid." International Conference Proceedings on Electrical and Control Engineering (http://ieeexplore.ieee.org/ xpls/abs_all.jsp?arnumber $=6057500 \& \operatorname{tag}=1)$.

Linvill, C., J. Shenot, and J. Lazar (2013). Designing Distributed Generation Tariffs Well: Fair Compensation in a Time of Transition. The Regulatory Assistance Project (www.raponline.org).

London Economics International (2013). "Estimating the Value of Lost Load." Briefing Paper Prepared for the Electric Reliability Council of Texas (http://www.ercot.com/content/gridinfo/resource/2015/mktanalysis/ERCOT_Valueof LostLoad_LiteratureReviewandMacroeconomic.pdf).

Mansur, E. (2008). "Measuring Welfare in Restructured Electricity Markets." Review of Economics and Statistics 90(2): 369-386. http://dx.doi.org/10.1162/rest.90.2.369.

Minnesota Department of Commerce (2014). Minnesota Value of Solar: Methodology. Division of Energy Resources Report (https://mn.gov/commerce/energy/images/MN-VOS-Methodology-FINAL.pdf).

Narayan, P. and R. Smyth (2005). "The Residential Demand For Electricity in Australia: An Application of the Bounds Testing Approach to Cointegration.” Energy Policy 33(4): 467-474. http://dx.doi.org/10.1016/j.enpol.2003.08.011.

North Carolina Clean Energy Technology Center (NCCETC) (2014). Rethinking Standby \& Fixed Charges: Regulatory \& Rate Design Pathways to Deeper Solar PV Cost Reductions (http://www.seia.org/sites/default/files/resources/RethinkingStandby-and-Fixed-Cost-Charges_V2.pdf).

NCCETC (2015a). Personal Tax Credit by State (http://programs.dsireusa.org/system/program?type =31\&technology $=7 \&)$.

NCCETC (2015b). Solar Rebate Program by State (http://programs.dsireusa.org/system/program?type = 88\&technology $=7 \&$ ).

NCCETC (2015c). Solar Renewable Energy Credit Program by State (http://programs.dsireusa.org/system/program?type $=85 \&)$.

NCCETC (2015d). The 50 States of Solar: A Quarterly Look at America's Fast-Evolving Distributed Solar Policy \& Regulatory Conversation (https://nccleantech.ncsu.edu/wp-content/uploads/The-50-States-of-Solar_FINAL.pdf).

Parsons and Brinckerhoff (2012). Electricity Transmission Costing Study. An Independent Report Endorsed by the Institution of Engineering and Technology (http://renewables-grid.eu/uploads/media/Electricity_Transmission_Costing_Study_ Parsons_Brinckerhoff.pdf).

Paul, A., E. Myers, and K. Palmer (2009). "A Partial Adjustment Model of U.S. Electricity Demand by Region, Season, and Sector." Resources for the Future Discussion Paper RFF DP 08-50 (http://www.rff.org/files/sharepoint/WorkImages/ Download/RFF-DP-08-50.pdf).

Poullikkas, A. (2013). "A Comparative Assessment of Net Metering and Feed in Tariff Schemes for Residential PV Systems.” Sustainable Energy Technologies and Assessments 3: 1-8. http://dx.doi.org/10.1016/j.seta.2013.04.001.

Puller, S. (2007). "Pricing and Firm Conduct in California's Deregulated Electricity Market." Review of Economics and Statistics 89(1): 75-87. http://dx.doi.org/10.1162/rest.89.1.75.

Ramsey, F. (1927). “A Contribution to the Theory of Taxation.” Economic Journal 37(1): 47-61. http://dx.doi.org/10.2307/ 2222721 .

Raskin, D. (2013). “The Regulatory Challenge of Distributed Generation.” Harvard Business Law Review Online 4: 38-51.

Schneider, J. and R. Sargent (2014). "Lighting the Way: The Top Ten States that Helped Drive America's Solar Energy Boom in 2013." PennEnvironment Research \& Policy Center Report (http://environmentamericacenter.org/sites/environment/files/reports/EA_Lightingtheway_scrn.pdf).

Solar Electric Power Association (2013). Ratemaking, Solar Value, and Solar Net Energy Metering-A Primer (http:// www.solarelectricpower.org/media/51299/sepa-nem-report-0713-print.pdf).

Taylor, T., P. Schwarz, and J. Cochell (2005). "24/7 Hourly Response to Electricity Real-Time Pricing with up to Eight Summers of Experience." Journal of Regulatory Economics 27(3): 235-262. http://dx.doi.org/10.1007/s11149-005-66236.

Than, K. (2013). “As Solar Power Grows, Dispute Flares Over U.S. Utility Bills.” National Geographic Daily News, December 24 (http://news.nationalgeographic.com/news/ energy/2013/12/131226-utilities-dispute-net-metering-for-solar/ ).

U.S. Federal Energy Commission (FERC) (2014). Price Formation in Organized Wholesale Electricity Markets. Staff Analysis of Energy Offer Mitigation in RTO and ISO Markets, Docket No. AD14-14-000 (https://www.ferc.gov/legal/ staff-reports/2014/AD14-14-mitigation-rto-iso-markets.pdf).

U.S. Energy Information Administration (2014a). Reporting of Greenhouse Gases Program. Table of Fuel and Energy Source: Codes and Emissions Coefficients. EIA Office of Integrated Analysis and Forecasting (http://www.eia.gov/oiaf/ 1605/coefficients.html). 
U.S. Energy Information Administration (2014b). State Electricity Profiles. Table 10. Supply and Disposition of Electricity (http://www.eia.gov/electricity/state/).

U.S. Energy Information Administration (2015a). "Levelized Cost and Levelized Avoided Cost of New Generation Resources.” Annual Energy Outlook (http://www.eia.gov/forecasts/aeo/pdf/electricity_generation.pdf).

U.S. Energy Information Administration (2015b). Form 826 (http://www.eia.gov/electricity/data/eia826).

U.S. Energy Information Administration (2015c). Detailed State Data (http://www.eia.gov/electricity/data/state).

U.S. Environmental Protection Agency (EPA) (2013). Regulatory Impact Analysis for the Proposed Standards of Performance for Greenhouse Gas Emissions for New Stationary Sources: Electric Utility Generating Units. EPA-452/R-13-003 (http://www2.epa.gov/sites/production/files/2013-09/documents/20130920proposalria.pdf).

Wade, S. (2003). "Price Responsiveness in the AEO2003 NEMS Residential and Commercial Buildings Sector Models." Report Prepared for the U.S. Energy Information Administration (http://www.eia.gov/oiaf/analysispaper/elasticity/pdf/ buildings.pdf).

Weissman, S. and N. Johnson (2012). The Statewide Benefits of Net-Metering in California \& the Consequences of Changes to the Program. Center for Law, Energy \& the Environment, University of California (http://www.law.berkeley.edu/files/ The_Statewide_Benefits_of_Net-Metering_in_CA_Weissman_and_Johnson.pdf).

World Alliance for Decentralized Energy (2014). Where Can DE be Used? (http://www.localpower.org/deb_where.html), visited September 21, 2014

Yamamoto, Y. (2012). "Pricing Electricity from Residential Photovoltaic Systems: A Comparison of Feed-in Tariffs, Net Metering, and Net Purchase and Sale.” Solar Energy 86(9): 2678-2685. http://dx.doi.org/10.1016/j.solener.2012.06.001. 